\title{
DFT insights into the electronic structure, mechanical behaviour, lattice dynamics and defect processes in the first Sc-based MAX phase Sc2SnC
}

M. A. Hadi ( $\sim$ hadipab@gmail.com )

University of Rajshahi

S.-R. G. Christopoulos

Coventry University

A. Chroneos

University of Thessaly

S. H. Naqib

University of Rajshahi

A. K.M.A. Islam

University of Rajshahi

Research Article

Keywords: sc2snc, m2snc, family, properties, phases

Posted Date: September 8th, 2021

DOl: https://doi.org/10.21203/rs.3.rs-870934/v1

License: (9) This work is licensed under a Creative Commons Attribution 4.0 International License.

Read Full License 


\title{
DFT insights into the electronic structure, mechanical behaviour, lattice
}

\section{dynamics and defect processes in the first Sc-based MAX phase $\mathrm{Sc}_{2} \mathrm{SnC}$}

\author{
M.A. Hadi ${ }^{*}$, S.-R.G. Christopoulos ${ }^{2}$, A. Chroneos ${ }^{3,4}$, S.H. Naqib ${ }^{1}$, A.K.M.A. Islam ${ }^{1,5}$ \\ ${ }^{1}$ Department of Physics, University of Rajshahi, Rajshahi 6205, Bangladesh \\ ${ }^{2}$ Faculty of Engineering, Environment and Computing, Coventry University, Priory Street, Coventry CV1 5FB, UK \\ ${ }^{3}$ Department of Electrical and Computer Engineering, University of Thessaly, 38221 Volos, Greece \\ ${ }^{4}$ Department of Materials, Imperial College, London SW7 2AZ, UK \\ ${ }^{5}$ International Islamic University Chittagong, Kumira, Chittagong-4318, Bangladesh \\ *Correspondence: hadipab@gmail.com
}

\begin{abstract}
The ceramic and metallic properties of the MAX phases make them attractive for numerous technological applications. The very recent experimental synthesis of the first scandium (Sc) based MAX phase $\mathrm{Sc}_{2} \mathrm{SnC}$ is an important addition to the MAX phase family as it further expands the diversity of physical characteristics of this family. Here we employ density functional theory (DFT) calculations to investigate the structural, electronic, mechanical, lattice dynamical properties of $\mathrm{Sc}_{2} \mathrm{SnC}$ including defect processes to compare with those of existing $\mathrm{M}_{2} \mathrm{SnC}$ phases. The calculated structural properties are in good agreement with the experimental values. The new phase $\mathrm{Sc}_{2} \mathrm{SnC}_{\mathrm{C}}$ is structurally, mechanically and dynamically stable. $\mathrm{Sc}_{2} \mathrm{SnC}$ is metallic with a mixture of covalent and ionic character. The covalency of $\mathrm{Sc}_{2} \mathrm{SnC}$ including $\mathrm{M}_{2} \mathrm{SnC}$ is mostly controlled by the effective valence. $\mathrm{Sc}_{2} \mathrm{SnC}$ in $\mathrm{M}_{2} \mathrm{SnC}$ family ranks second in the scale of deformability, softness and machinability. The elastic anisotropy level in $\mathrm{Sc}_{2} \mathrm{SnC}$ is moderate compared to the other $\mathrm{M}_{2} \mathrm{SnC}$ phases. Like other members of the $\mathrm{M}_{2} \mathrm{SnC}$ family, $\mathrm{Sc}_{2} \mathrm{SnC}$ has the potential to be etched into $2 \mathrm{D}$ MXenes and has the potential to be a thermal barrier coating (TBC) material. The hardness and melting point of $\mathrm{Sc}_{2} \mathrm{SnC}$, including $\mathrm{M}_{2} \mathrm{SnC}$, follows the trend of bulk modulus.
\end{abstract}

\section{Introduction}

Compounds of the ternary laminated family, discovered six decades ago as the $\mathrm{H}$-phases, are now referred to as the MAX phases ${ }^{1,2}$. This family is chemically represented by $M_{n+1} A X_{n}$, where $M$ is a transition metal, $\mathrm{A}$ is an A-group element and $\mathrm{X}$ is either carbon or nitrogen or boron ${ }^{3}$. The integer $n$ is called the layer index of the M atom. According to $n$, the MAX family is divided into six sub-families so far, such $211,312,413,514,615$, and 716 MAX phases $^{3}$. This family has also been described as metallic ceramics as they combine some metallic and ceramic properties ${ }^{3}$. Similar to metals, some MAX phases are electrically and thermally conductive, resistant to thermal shock, damage tolerant, and readily machinable. Again, they resemble ceramics, as some of them are lightweight, wear resistant, elastically rigid, brittle, and resistant to oxidation and corrosion.

The crystal structure of MAX phases consists of nearly close-packed layers of $\mathrm{MX}_{6}$ octahedra interpolated with square-planar slabs of A-atomic layers. In these the $\mathrm{X}$ atoms occupy the octahedral sites between the $\mathrm{M}$-atoms. The $\mathrm{A}$ atoms reside in the center of trigonal prisms, which are slightly larger than the octahedral sites so as to better accommodate the relatively large $A$-atoms ${ }^{4}$. The interposing pure A-element planes are mirror planes to the zigzagging $M_{n+1} X_{n}$-slabs. Alternatively, the structure of the MAX phases consists of highly symmetrical unit cells that are atomically layered along the c-axis. In the unit cell, the $(n+1)$ ceramic MX-layers are stacked along the c-axis between the two metallic A-layers. The thickness of these atomic layers is within the nanometer range and this is the reason MAX phases are sometimes termed as nanolaminates. The periodic arrangement of the metallic and ceramic layers is responsible for the metallic and ceramic properties of the MAX 
phases. MAX phases have numerous potential applications ranging from aerospace to nuclear reactors $^{5}$. Recently, MAX phases are used to derive the two-dimensional MXenes, which are being used as energy storage materials and as electrodes in electrochemical capacitors, micro-

supercapacitors, and batteries ${ }^{6}$.

Interest in the Sn-containing MAX phase is high in the community due to the report on attractive electrochemical performance of $\mathrm{Nb}_{2} \mathrm{SnC}$ in Li-ion electrolytes ${ }^{7}$. Importantly, two of the three MAX phases discovered after this report are $\mathrm{Sn}$-based MAX Phases. These new members in MAX family are $\mathrm{V}_{2} \mathrm{SnC}^{8}, \mathrm{Zr}_{2} \mathrm{SeC}^{9}$, and $\mathrm{Sc}_{2} \mathrm{SnC}^{10}$. The last one is the first Sc-based MAX phase reported with full crystallographic information. Previously, $\mathrm{Sc}_{2} \mathrm{InC}$ was included into a list for $\mathrm{H}$-phases, however, without any crystallographic data ${ }^{11}$. The source was mentioned as private communication. Up to now there is no experimental evidence of synthesis and characterization of $\mathrm{Sc}_{2} \mathrm{InC}$. Therefore, it can be inferred that $\mathrm{Sc}_{2} \mathrm{SnC}$ is the first Sc-based compound in MAX family. $\mathrm{Sc}_{2} \mathrm{SnC}$ is also exceptional for another reason. The $\mathrm{M}$-element $\mathrm{Sc}$ of $\mathrm{Sc}_{2} \mathrm{SnC}$ is a rare-earth element, which, in general, in the MAX compounds is typically a transition metal. This uniqueness of $\mathrm{Sc}_{2} \mathrm{SnC}$ encouraged the present DFT investigation. Here we aim to calculate the structural, electronic, mechanical, and thermal properties including Vickers hardness and defect processes of $\mathrm{Sc}_{2} \mathrm{SnC}$. The derived properties are compared with those found for previously synthesized other $\mathrm{M}_{2} \mathrm{SnC}$ MAX phases.

\section{Computational methods}

The present DFT calculations were performed using the CASTEP code ${ }^{12}$. The Perdew-Burke-Ernzerhof (PBE) functional within the generalized gradient approximation (GGA) was used to evaluate the electronic exchange-correlation energy ${ }^{13}$. Ultra-soft pseudo-potential proposed by Vanderbilt is chosen to model the interactions between electrons and ion cores ${ }^{14}$. The Monkhorst-Pack (MP) scheme with a $\Gamma$-centered k-point mesh of $15 \times 15 \times 3$ grid is employed to integrate over the first Brillouin zone in the reciprocal space of hexagonal unit cell of $\mathrm{Sc}_{2} \mathrm{SnC}^{15}$. A cutoff energy of $700 \mathrm{eV}$ is preferred to expand the eigenfunctions of the valence and nearly valence electrons using a planewave basis. During the geometry optimization, both the total energy and internal forces are minimized with the Broyden-Fletcher-Goldfarb-Shanno (BFGS) algorithm ${ }^{16}$. To achieve the selfconsistent convergence the difference in the total energy is kept less than $5 \times 10^{-6} \mathrm{eV} / \mathrm{atom}$, the maximum ionic Hellmann-Feynman force less than $0.01 \mathrm{eV} / \AA$, maximum ionic displacement less than $5 \times 10^{-4} \AA$, and maximum stress less than $0.02 \mathrm{GPa}$.

The elastic properties are investigated within the first-principles method using finite-strain theory embedded in the CASTEP code ${ }^{17}$. In this method, a predetermined value for strain is used to relax all the free parameters and compute the stress. For elastic calculations, the convergence criteria are set as: the difference in total energy less than $10^{-6} \mathrm{eV} / \mathrm{atom}$, the maximum ionic Hellmann-Feynman force less than $2 \times 10^{-3} \mathrm{eV} / \AA$, and the maximum ionic displacement less than $10^{-4} \AA$. The finite-strain theory as implemented in CASTEP has been successfully employed to calculate the elastic properties of numerous systems ${ }^{18-29}$.

Lattice dynamic properties such as phonon dispersion and phonon density of states are calculated using a $3 \times 3 \times 1$ supercell employing the finite displacement supercell method within the code. A $35 \times 35 \times 7 \mathrm{k}$-point mesh was used to calculate the electronic charge density distribution and the Fermi surface. Defect calculations were carried out with a supercell of 72 -atomic site (36M, 18A, and $18 \mathrm{C})$ using a $3 \times 3 \times 1$ grid k-point mesh within the MP scheme under constant pressure. To determine the potential interstitial sites a thorough computational search was performed examining all potential interstitial sites.

\section{Results and discussions}

Structural properties: Commonly with other MAX phases $\mathrm{Sc}_{2} \mathrm{SnC}$ crystallizes in the hexagonal space group $P 6_{3} / \mathrm{mmc}$ (No. 194). Each unit cell of $\mathrm{Sc}_{2} \mathrm{SnC}$ contains two formula units and eight atoms (refer to Figure $1(a))$. The Sc atoms occupy the $4 f$ Wyckoff site with the fractional coordinates $(1 / 3,2 / 3, z)$, 
the $\mathrm{Sn}$ resides in the $2 d$ atomic site with the fractional coordinates $(1 / 3,2 / 3,3 / 4)$ and the $C$ atoms take position at the $2 \mathrm{a}$ Wyckoff position with the fractional coordinates $(0,0,0)$. The optimized lattice parameters are listed in Table $\mathrm{S} 1$ in the supplementary section along with those of all $\mathrm{M}_{2} \mathrm{SnC}$ MAX phases including experimental values, ${ }^{8,10,30-32}$. The present values for $\mathrm{Sc}_{2} \mathrm{SnC}$ show very good agreement with the experimental values, suggesting the validity of the present investigation. In previous studies ${ }^{30,31}$, we observed that the lattice constants of Sn-based 211 MAX phases maintain a good relation with the crystal radius of $\mathrm{M}$-atoms. Both lattice constants $a$ and $c$ increase almost linearly with the crystal radius of $\mathrm{M}$-atoms. The $\mathrm{Sn}$-based new compound $\mathrm{Sc}_{2} \mathrm{SnC}$ also maintains this relationship (see Figure $1(\mathrm{~b})$ and (c)).
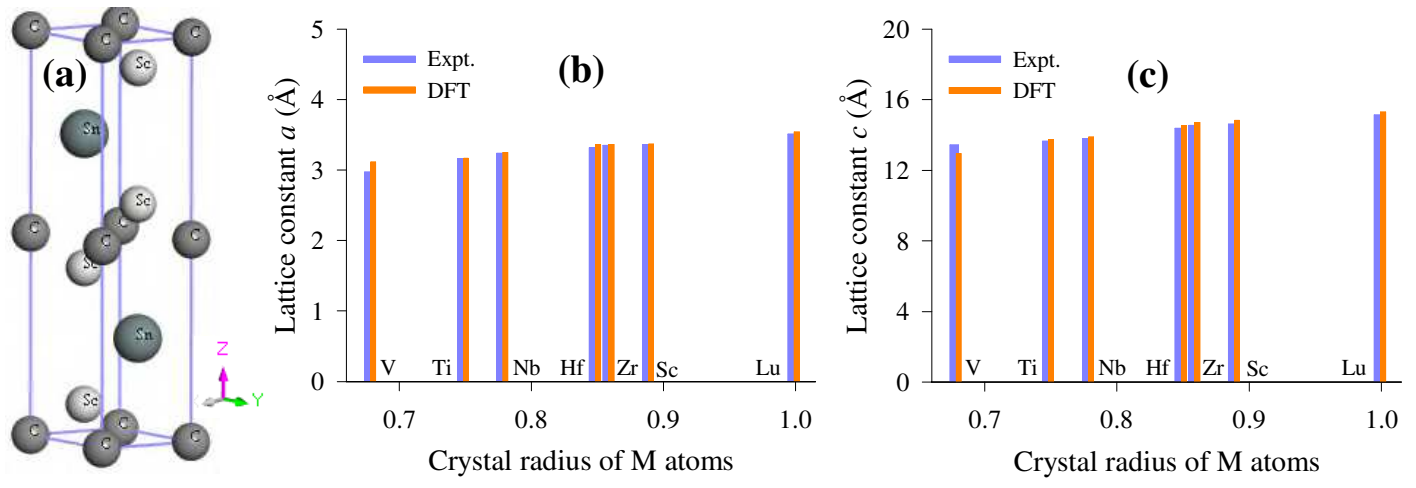

Figure 1. (a) Unit cell of $\mathrm{Sc}_{2} \mathrm{SnC}$; (b) and (c) lattice constants as a function of crystal radius of $\mathrm{M}$ atoms.

\section{Electronic properties:}

Electronic band structure, electronic density of states (DOS), charge density map, Fermi surface, Mulliken population analysis are investigated to describe the electronic and bonding features of $\mathrm{Sc}_{2} \mathrm{SnC}$, a compound in $\mathrm{M}_{2} \mathrm{SnC}$ MAX family.

Band structure and DOS: The electronic band structure of $\mathrm{Sc}_{2} \mathrm{SnC}$ was calculated along the high symmetry directions in the first Brillouin zone and is shown in Figure 2a. It reveals the metallic characteristics of $\mathrm{Sc}_{2} \mathrm{SnC}$, which are similar to other MAX phases including $\mathrm{M}_{2} \mathrm{SnC}$ as the valence band crosses the Fermi level $E_{\mathrm{F}}$ and overlaps with the conduction band. The Fermi level of $\mathrm{Sc}_{2} \mathrm{SnC}$ intersects the crossing bands roughly along the middle and is located at about equal energies from both the pure valence and conduction bands. On the other hand, the Fermi level in $\mathrm{V}_{2} \mathrm{SnC}$ and $\mathrm{Ti}_{2} \mathrm{SnC}$ lies just below the valence band maximum nearby the $\Gamma$-point ${ }^{4,30}$. The $\Gamma$-point, where most of the valence bands accumulate, shifts upwards for other $\mathrm{M}_{2} \mathrm{SnC}$ MAX phases (see Fig. 6 in Ref. 4). The distance of this point from Fermi level increases following the order: $\mathrm{Ti}_{2} \mathrm{SnC}<\mathrm{V}_{2} \mathrm{SnC}<\mathrm{Nb}_{2} \mathrm{SnC}<$ $\mathrm{Zr}_{2} \mathrm{SnC}<\mathrm{Hf}_{2} \mathrm{SnC}<\mathrm{Sc}_{2} \mathrm{SnC}<\mathrm{Lu}_{2} \mathrm{SnC}$. The band features of the $\mathrm{Sc}_{2} \mathrm{SnC}$ are very similar to that of the $\mathrm{Lu}_{2} \mathrm{SnC}$ compared to other $\mathrm{M}_{2} \mathrm{SnC}$ phases ${ }^{4}$. A notable feature in the band structure is the considerably anisotropic nature with low energy dispersion along the c-axis. This is apparent from the reduced dispersion along the short $\mathrm{H}-\mathrm{K}$ and $\mathrm{M}-\mathrm{L}$ directions. The anisotropic nature of the band structure near and below the Fermi level indicates that the electrical conductivity is as anisotropic for the $\mathrm{Sc}_{2} \mathrm{SnC}$ as for the other $\mathrm{M}_{2} \mathrm{SnC}$ MAX phases.

To obtain more information on the chemical bonding in $\mathrm{Sc}_{2} \mathrm{SnC}$, the total and partial densities of states were calculated and are shown in Figure $2 \mathrm{~b}$. In this figure, the broken vertical green line refers to the Fermi level $E_{\mathrm{F}}$, which is located to the left of a pseudogap in the total DOS. It is one of the indications of the structural stability of $\mathrm{Sc}_{2} \mathrm{SnC}$. The greater proximity of $E_{\mathrm{F}}$ to the pseudogap indicates greater structural stability of the compound. Comparing the position of $E_{\mathrm{F}}$ relative to the pseudogap for all existing $\mathrm{M}_{2} \mathrm{SnC}$ MAX phases the structural stability should follow the order: $\mathrm{Nb}_{2} \mathrm{SnC}$ 
$>\mathrm{Ti}_{2} \mathrm{SnC}>\mathrm{Lu}_{2} \mathrm{SnC}>\mathrm{Zr}_{2} \mathrm{SnC}>\mathrm{Hf}_{2} \mathrm{SnC}>\mathrm{Sc}_{2} \mathrm{SnC}>\mathrm{V}_{2} \mathrm{SnC}$. The main contribution to the total DOS at $E_{\mathrm{F}}$ comes from the $\mathrm{d}$ orbital of Sc. The d-resonance at the surroundings of $E_{\mathrm{F}}$ and the finite value of the total DOS at $E_{\mathrm{F}}$ indicates the metallic character of $\mathrm{Sc}_{2} \mathrm{SnC}$ and this is a common feature of MAX phases. The total DOS of $\mathrm{Sc}_{2} \mathrm{SnC}$ at $E_{\mathrm{F}}$ is 3.10 states/eV-uc, which is about half of $\mathrm{V}_{2} \mathrm{SnC}$ ( 6.12 states/eV-uc) and between the range (2.35 - 3.93 states/eV-uc) of other $\mathrm{M}_{2} \mathrm{SnC}$ phases ${ }^{4,30}$.
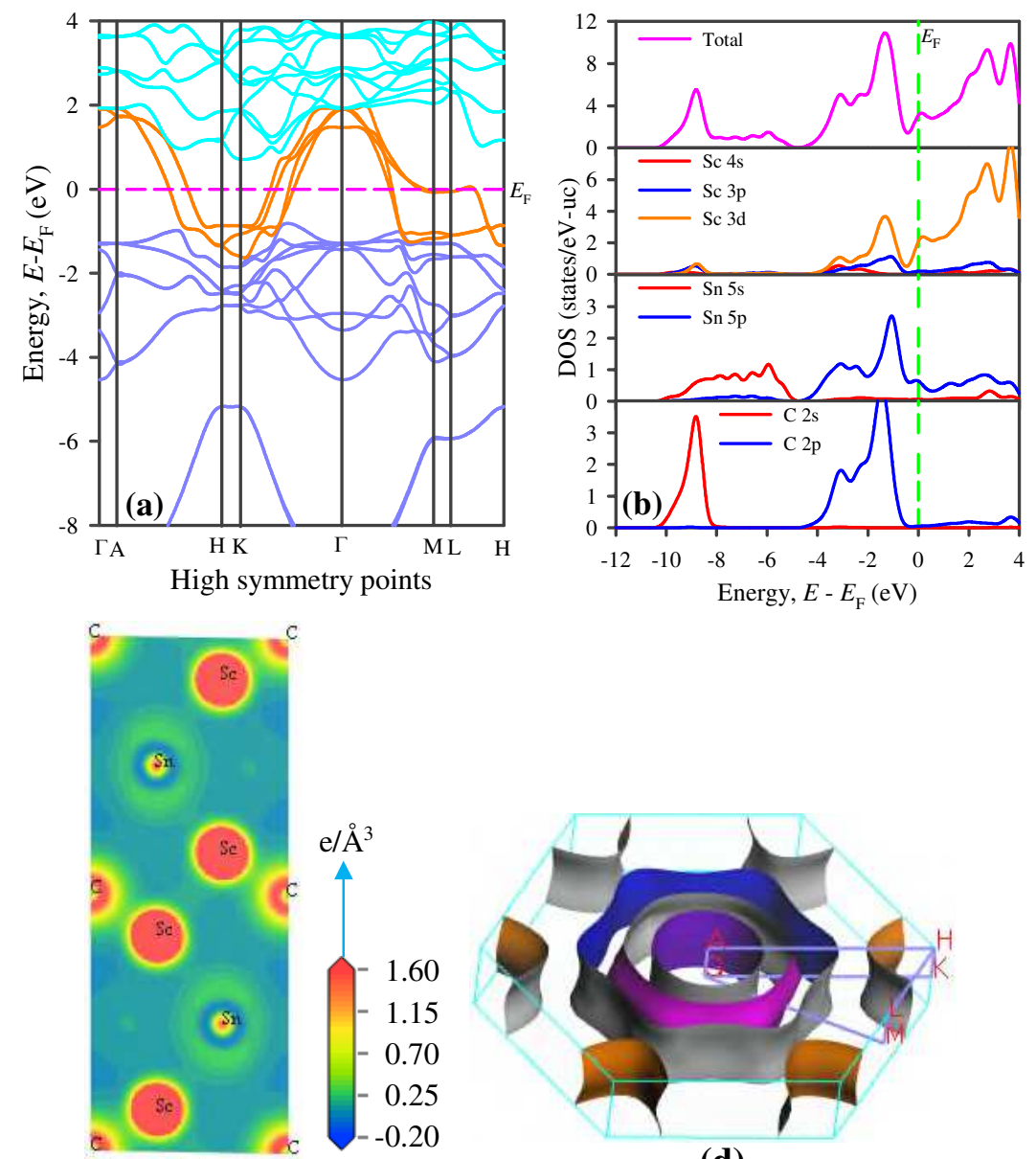

(c)

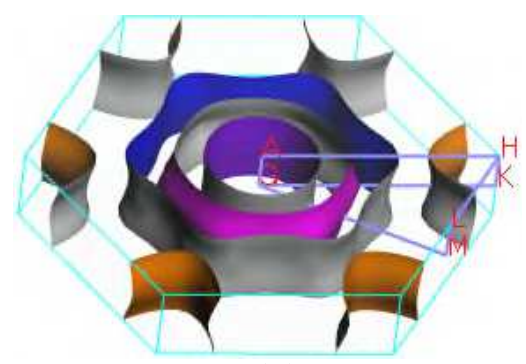

(d)

Figure 2. (a) Band structure, (b) Density of states, (c) Charge density map and (d) Fermi surface of $\mathrm{Sc}_{2} \mathrm{SnC}$.

The valence band of $\mathrm{Sc}_{2} \mathrm{SnC}$ is divided into two main parts. The lower part is situated between $10.4 \mathrm{eV}$ and $-4.9 \mathrm{eV}$, which contains a distinct peak and a flat region. The peak originates as a result of hybridization between Sc $3 \mathrm{~d}$ and $\mathrm{C} 2 \mathrm{~s}$ orbitals, indicating covalent Sc-C bonding. The flat region arises due to the main contribution of $\mathrm{Sn} 5 \mathrm{~s}$ electrons. The upper valence band consists of two distinct peaks. The highest peak close to $E_{\mathrm{F}}$ is also due to the hybridization of Sc $3 \mathrm{~d}$ electrons with $\mathrm{C}$ $2 p$ electrons. Hybridization between $S c 3 p$ and $S n 5 p$ near the $E_{F}$ also contributes to the highest peak of the total DOS. This hybridization leads to the formation of the Sc-Sn covalent bond between Sc and $\mathrm{Sn}$. This bond is not as strong as Sc-C because the corresponding peak is closer to the Fermi level. The lowest peak centered at $-3.3 \mathrm{eV}$ arises due to the interaction between $\mathrm{Sc} 3 \mathrm{~d}$ and $\mathrm{C} 2 \mathrm{p}$ states. The bonding nature of $\mathrm{Sc}_{2} \mathrm{SnC}$ is almost same of other $\mathrm{M}_{2} \mathrm{SnC}$ MAX phases. Overall, the bonding character in $\mathrm{Sc}_{2} \mathrm{SnC}$ is a combination of metallic, covalent, and, owing to the difference in electronegativity between the comprising elements, ionic like other MAX phase compounds. 
Charge density: The contour map of the electron charge distribution among the comprising atoms in a compound is a way to understand the nature of atomic bonding in the material. The contour map for $\mathrm{Sc}_{2} \mathrm{SnC}$ is given in Figure $2 \mathrm{c}$. It can be observed that the charge distributions around the atoms have created an almost spherical electron cloud and its intensity determines the amount of charge accumulation. The amount of charge accumulated around the $\mathrm{Sc}$ atom is $0.53 \mathrm{e}$, while the amount of charge accumulated around the $M$ atom of other $M_{2} S n C$ phases is between $0.28-0.45 e$ 4,30 . Clearly, the maximum charge accumulates around the $\mathrm{Sc}$ atom among all $\mathrm{M}$-atoms in $\mathrm{M}_{2} \mathrm{SnC}$ phases. The minimum charge is found to accumulate around $\mathrm{Hf}^{4}$. The electron cloud of Sc-charge overlaps with that of C-charge and slightly edges with that of Sn-charge, which indicates the stronger covalent Sc-C and weaker covalent Sc-Sn bonding, respectively. The spherical distribution of charge around the atoms is an indication of some ionic character in chemical bonds in $\mathrm{Sc}_{2} \mathrm{SnC}$. The contour map of electron charge distribution for $\mathrm{Sc}_{2} \mathrm{SnC}$ is almost identical to those of other $\mathrm{M}_{2} \mathrm{SnC}$ phases.

Fermi surface: The Fermi surface (FS) is a conceptual surface in reciprocal space that separates occupied electron states from unoccupied ones at zero temperature. The dynamical properties of an electron on the FS mostly depend on where it is located on the FS, and the shape of the FS with respect to the Brillouin zone can serve as a guide to the electrical properties of a metallic system. Currently, the presence of a FS is likely the utmost significant signature of the entity of Fermi liquid quasiparticles in a material. Indeed, the FS is related to a range of interesting physical phenomena. The FS of $\mathrm{Sc}_{2} \mathrm{SnC}$ was calculated and is shown in Figure $2 \mathrm{~d}$. The FS consists of four Fermi sheets centered along the $\Gamma-A$ direction. The three Fermi sheets close to the center of the Brillouin zone have cylindrical or prismatic-like hexagonal cross sections. These are 2D-like electron sheets. The remaining sheet consists of six separate parts parallel to the $\mathrm{H}-\mathrm{K}$ directions. This sheet is hole-like and situated at the corners of the Brillouin zone around the $\mathrm{H}-\mathrm{K}$ directions. In comparison to the FSs of $\mathrm{M}_{2} \mathrm{SnC}$ family, the FS of $\mathrm{Sc}_{2} \mathrm{SnC}$ is very similar to that of $\mathrm{Lu}_{2} \mathrm{SnC}$ and simple enough compared to the FSs of other $\mathrm{M}_{2} \mathrm{SnC}$ phases ${ }^{4,30}$. The non-spherical shape of the Fermi sheets is an indication of the metallic conductivity of $\mathrm{Sc}_{2} \mathrm{SnC}$.

Mulliken population: Population analysis in CASTEP is carried out using a projection of the planewave (PW) states onto a linear combination of atomic orbitals (LCAO) localized basis using a method developed by Sanchez-Portal et al. ${ }^{33}$. Population analysis of the resultant projected states is then accomplished using the Mulliken formalism ${ }^{34}$. This analysis provides the Mulliken charge, bond population and bond length in a bulk material. Mulliken charge associated with a given atom, A, can be determined as:

$Q(A)=\sum_{k} \omega_{k} \sum \sum_{\mu}^{o n} \sum_{v} P_{\mu v}(k) S_{\mu v}(k)$

where $P_{\mu v}(k)$ is the density matrix and $S_{\mu v}(k)$ is overlap matrix. The bond population between two atoms $A$ and $B$ can be calculated as:

$P(A B)=\sum_{k} \omega_{k} \sum \sum_{\mu}^{\text {on } A} \sum_{v}^{\text {on } B} 2 P_{\mu v}(k) S_{\mu v}(k)$

The Mulliken charge measures the effective valence from the absolute difference between the formal ionic charge and the Mulliken charge on the atomic species. Table S2 lists the effective valence, bond population, and bond length between different atoms in $\mathrm{Sc}_{2} \mathrm{SnC}$ and existing $\mathrm{M}_{2} \mathrm{SnC}$ MAX phases. The pure valence states for transition metals Sc, Ti, V, $\mathrm{Zr}, \mathrm{Nb}$, $\mathrm{Lu}$, and $\mathrm{Hf}$ in $\mathrm{M}_{2} \mathrm{SnC}$ MAX phases are $3 d^{1}, 3 d^{2}, 3 d^{3}, 4 d^{2}, 4 d^{4} 5 s^{1}, 5 d^{1}, 5 d^{2}$, respectively. It is observed that the effective valence largely depends on the $d$-orbital electrons of the transition metals. It increases when the transition metal moves from the left to the right in the periodic table. Its non-zero positive value is an indication of mixed covalent and ionic nature in chemical bonds. Its progression towards zero value indicates an increase in the level of ionicity. Its zero value implies an ideal ionic character in a 
chemical bond. Its progression from zero with a positive value indicates an increase in covalency level of chemical bonds. Based on the effective valence the covalency of $\mathrm{M}_{2} \mathrm{SnC}$ increase when $\mathrm{M}$ atoms move from the left to the right in the periodic table.

Bond population is another indication of bond covalency in a crystal as a high value of bond population in essence indicates a high degree of covalency in the chemical bond. The $\mathrm{M}-\mathrm{C}$ bond in the MAX phases is mainly covalent bond. The bond population of $\mathrm{M}-\mathrm{C}$ bond in each $\mathrm{M}_{2} \mathrm{SnC} \mathrm{MAX}$ phases is positive except in $\mathrm{Lu}_{2} \mathrm{SnC}$. The bond population of $\mathrm{M}-\mathrm{C}$ bond in $\mathrm{M}_{2} \mathrm{SnC}$ deceases when the $\mathrm{M}$ atom moves from the left to the right in the periodic table, indicating the decrease in covalency. Actually, effective valence and positive bond population combinedly control the covalency of crystalline solids. The bulk modulus is mostly controlled by the bond covalency. Between effective valence and positive bond population, which is most influential in bond covalency? This can be verified with the bulk modulus. It is observed from the Figure $4(\mathrm{a})$ in the next section that the bulk modulus changes according to the effective valence. Therefore, it can be concluded that the effective valence mainly controls the covalency level in a crystal. The bond length of covalent $M-C$ bond deceases when the $M$ atom moves from the left to the right in the periodic table. It is clear that the shorter the covalent bond length, the higher the bond covalency. A negative bond population indicates the antibonding state between two relevant atoms. Other bonds in $\mathrm{M}_{2} \mathrm{SnC} \mathrm{MAX}$ phases have negative bond population with the exception of the M-Sn bond in $\mathrm{Sc}_{2} \mathrm{SnC}$ and the $\mathrm{Sn}-\mathrm{C}$ bond in $\mathrm{Lu}_{2} \mathrm{SnC}$. Indeed, the $\mathrm{Sn}-\mathrm{C}$ bond is the source of the covalency in $\mathrm{Lu}_{2} \mathrm{SnC}$.

\section{Mechanical properties:}

Single crystal elastic constants, bulk elastic moduli, elastic anisotropy, Vickers hardness are calculated to describe the mechanical behaviors of $\mathrm{Sc}_{2} \mathrm{SnC}$ in comparison to existing $\mathrm{M}_{2} \mathrm{SnC}$ phases.

Single crystal elastic constants: Elastic constants are the fundamental tools for accessing the mechanical behavior of crystalline solids. MAX phases have five independent elastic constants $C_{\mathrm{ij}}$ due to their hexagonal crystal symmetry. These are $C_{11}, C_{33}, C_{44}, C_{12}$ and $C_{13}$. In addition they have one more dependent elastic constant $C_{66}$, which depends on $C_{11}$ and $C_{12}$ and $C_{66}=\left(C_{11}-C_{12}\right) / 2$. First of all, the elastic constants justify the mechanical stability of compounds obeying Born criteria. For hexagonal systems these criteria are as follows ${ }^{35}$ :

$C_{11}, C_{33}, C_{44}>0 ; C_{11}>\left|C_{12}\right|$ and $\left(C_{11}+C_{12}\right) C_{33}>2 C_{13} C_{13}$

The calculated elastic constants of $\mathrm{Sc}_{2} \mathrm{SnC}$ are listed in Table $\mathrm{S} 3$ and shown in Fig. 3 along with CASTEP-derived elastic constants for existing $\mathrm{M}_{2} \mathrm{SnC}$ phases for comparison. $\mathrm{Sc}_{2} \mathrm{SnC}_{\mathrm{C}}$ meets the above conditions by its elastic constants like its predecessors $\mathrm{M}_{2} \mathrm{SnC}$ and ensures its own mechanical stability like its predecessors.

The elastic constants $C_{11}$ and $C_{33}$ represent the elasticity in length, whereas other constants such as $C_{12}, C_{13}$, and $C_{44}$ are associated with elasticity in shape. Indeed, $C_{11}$ and $C_{33}$ represent the stiffness along the crystallographic a- and c-axis, respectively. The stiffness of $\mathrm{Sc}_{2} \mathrm{SnC}$ is slightly larger along the a-axis than along the c-axis, which is also observed for $\mathrm{Ti}_{2} \mathrm{SnC}, \mathrm{Nb}_{2} \mathrm{SnC}$ and $\mathrm{Hf}_{2} \mathrm{SnC}$. For the remaining $\mathrm{M}_{2} \mathrm{SnC}$ phases, $\mathrm{V}_{2} \mathrm{SnC}, \mathrm{Zr}_{2} \mathrm{SnC}$, and $\mathrm{Lu}_{2} \mathrm{SnC}$, the stiffness along the c-axis is slightly larger than that in the a-axis. The difference between $C_{11}$ and $C_{33}$ quantifies the level of elastic anisotropy in crystals relating to the crystallographic axis. Accordingly, $\mathrm{V}_{2} \mathrm{SnC}, \mathrm{Nb}_{2} \mathrm{SnC}$, and $\mathrm{Hf}_{2} \mathrm{SnC}$ are elastically more anisotropic than $\mathrm{Sc}_{2} \mathrm{SnC}, \mathrm{Ti}_{2} \mathrm{SnC}, \mathrm{Zr}_{2} \mathrm{SnC}$, and $\mathrm{Lu}_{2} \mathrm{SnC}$. The new phase $\mathrm{Sc}_{2} \mathrm{SnC}$ ranks fourth in the view of both less and high anisotropy in the $\mathrm{M}_{2} \mathrm{SnC}$ family of seven members.

Shear elastic constants $C_{12}$ and $C_{13}$ reciprocally lead to a functional stress component along the crystallographic a-axis with a uniaxial strain along the crystallographic b-and c-axis, respectively. This stress component takes the measurements of the shear deformation resistance of a compound

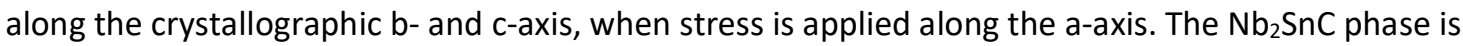
most capable of resisting such deformation, whereas $\mathrm{Lu}_{2} \mathrm{SnC}$ will easily deform under an equal stress along the a-axis. The new compound $\mathrm{Sc}_{2} \mathrm{SnC}$ will be the second in rank in $\mathrm{M}_{2} \mathrm{SnC}$ systems that will be 
easily deformed if a rank of deformation resistance of $\mathrm{M}_{2} \mathrm{SnC}$ system is made: $\mathrm{Nb}_{2} \mathrm{SnC}>\mathrm{V}_{2} \mathrm{SnC}>$ $\mathrm{Hf}_{2} \mathrm{SnC}>\mathrm{Ti}_{2} \mathrm{SnC}>\mathrm{Zr}_{2} \mathrm{SnC}>\mathrm{Sc}_{2} \mathrm{SnC}>\mathrm{Lu}_{2} \mathrm{SnC}$.

Elastic constant $C_{44}$ gives an indirect measure of the indentation hardness of a material. A low value of $C_{44}$ indicates higher shearability and low hardness of a compound. High shearability and low hardness are related to better machinability of a compound. Due to low value of $C_{44}$, $\mathrm{Lu}_{2} \mathrm{SnC}$ is the softest and most easily machinable among the seven $\mathrm{M}_{2} \mathrm{SnC} \mathrm{MAX}$ phases. The new material $\mathrm{Sc}_{2} \mathrm{SnC}$ should be the second in rank in the $\mathrm{M}_{2} \mathrm{SnC}$ systems that will be soft and easily machinable.

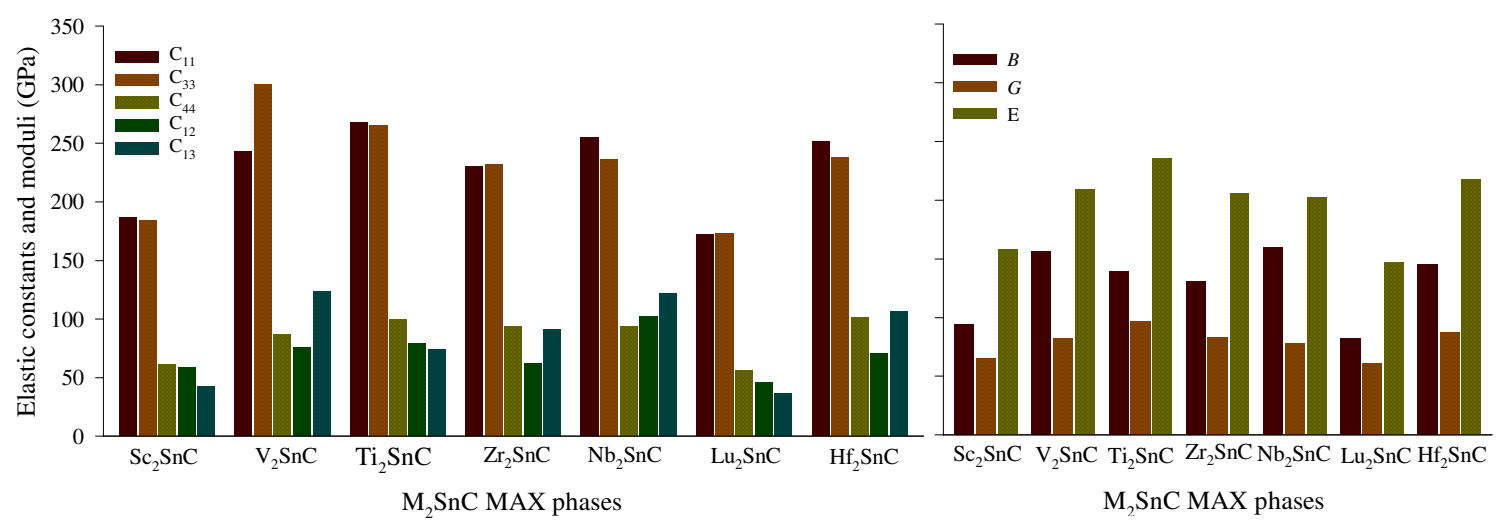

Figure 3. Elastic constants $C_{\mathrm{ij}}$ and moduli $B, G$, and $E$ of $\mathrm{SC}_{2} \mathrm{SnC}$ and other MAX phases.

The symmetry condition $C_{66}=\left(C_{11}-C_{12}\right) / 2$ represents an important consequence in hexagonal crystals. $C_{66}$ serves as the shear constant on the (100) plane in a [010] direction, while $\left(C_{11}-C_{12}\right) / 2$ stands for the shear constant on the (110) plane in a [110] direction. Therefore, the elastic shear constant is the same for all planes in the [001] zone, independent on the specific shear plane or shear direction, which known as transverse isotropy. This means that the elastic constants are invariant for arbitrary rotation around the z-axis: in the xy plane, the hexagonal crystals are elastically isotropic, which we will observe in a next section.

Bulk elastic moduli: Elastic moduli are the most important elastic parameters that assess the mechanical behavior of crystalline solids. Calculated elastic moduli are listed in Table S3 and shown in Figure 3. Bulk modulus $B$ and shear modulus $G$ can be derived from the elastic constants $C_{i j}$ using Voight-Reuss-Hill approximations ${ }^{36-38}$. A detailed discussion of these methods for hexagonal crystals is found in a recent study ${ }^{39}$. The bulk modulus of a crystal depends microscopically on the nature of its bond such as length and type. It is also controlled by the total effective valence of the crystal (refer to Fig. 4a). Bulk modulus measures the resistance to uniform compression of a material and is highly linked to chemical composition and crystal structure. Among $\mathrm{M}_{2} \mathrm{SnC}$ phases, the new phase $\mathrm{Sc}_{2} \mathrm{SnC}$ possesses the second lowest value for $B$. The highest value is assigned to $\mathrm{Nb}_{2} \mathrm{SnC}$ and the lowest value is associated with $\mathrm{Lu}_{2} \mathrm{SnC}$. Therefore, $\mathrm{Sc}_{2} \mathrm{SnC}$ will be compressed easily compared to existing $\mathrm{M}_{2} \mathrm{SnC}$ phases except $\mathrm{Lu}_{2} \mathrm{SnC}$. The shear modulus $G$ is concerned with the deformation of a solid material when it experiences a force parallel to one of its surfaces while its opposite face experiences an opposing force such as friction. $G$ maintains a good relationship with $C_{44}$. Here, it is reflected and $\mathrm{Sc}_{2} \mathrm{SnC}$ secure the second rank in the scale of lowest value of $G$ similar to $C_{44}$. Thus, $\mathrm{Sc}_{2} \mathrm{SnC}$ should be easily machinable than other $\mathrm{M}_{2} \mathrm{SnC}$ phases except $\mathrm{Lu}_{2} \mathrm{SnC}$.

$B$ and $G$ collectively prescribe an important parameter known as Pugh's ratio (defined as $B / G$ ) that evaluates a necessary mechanical behavior of crystalline solids ${ }^{40}$. Generally, a material is either considered brittle or ductile. In some cases, some materials behave neutral. A neutral material has a Pugh's ratio of 1.75 while the brittle materials have a value less than 1.75 and ductile materials possess a value greater than 1.75. Accordingly, $\mathrm{Sc}_{2} \mathrm{SnC}$ is a brittle material similar to $\mathrm{Ti}_{2} \mathrm{SnC}, \mathrm{Zr}_{2} \mathrm{SnC}$, $\mathrm{Lu}_{2} \mathrm{SnC}$ and $\mathrm{Hf}_{2} \mathrm{SnC}$ while $\mathrm{V}_{2} \mathrm{SnC}$ and $\mathrm{Nb}_{2} \mathrm{SnC}$ exhibit ductility (refer to Figure 4(b)). 

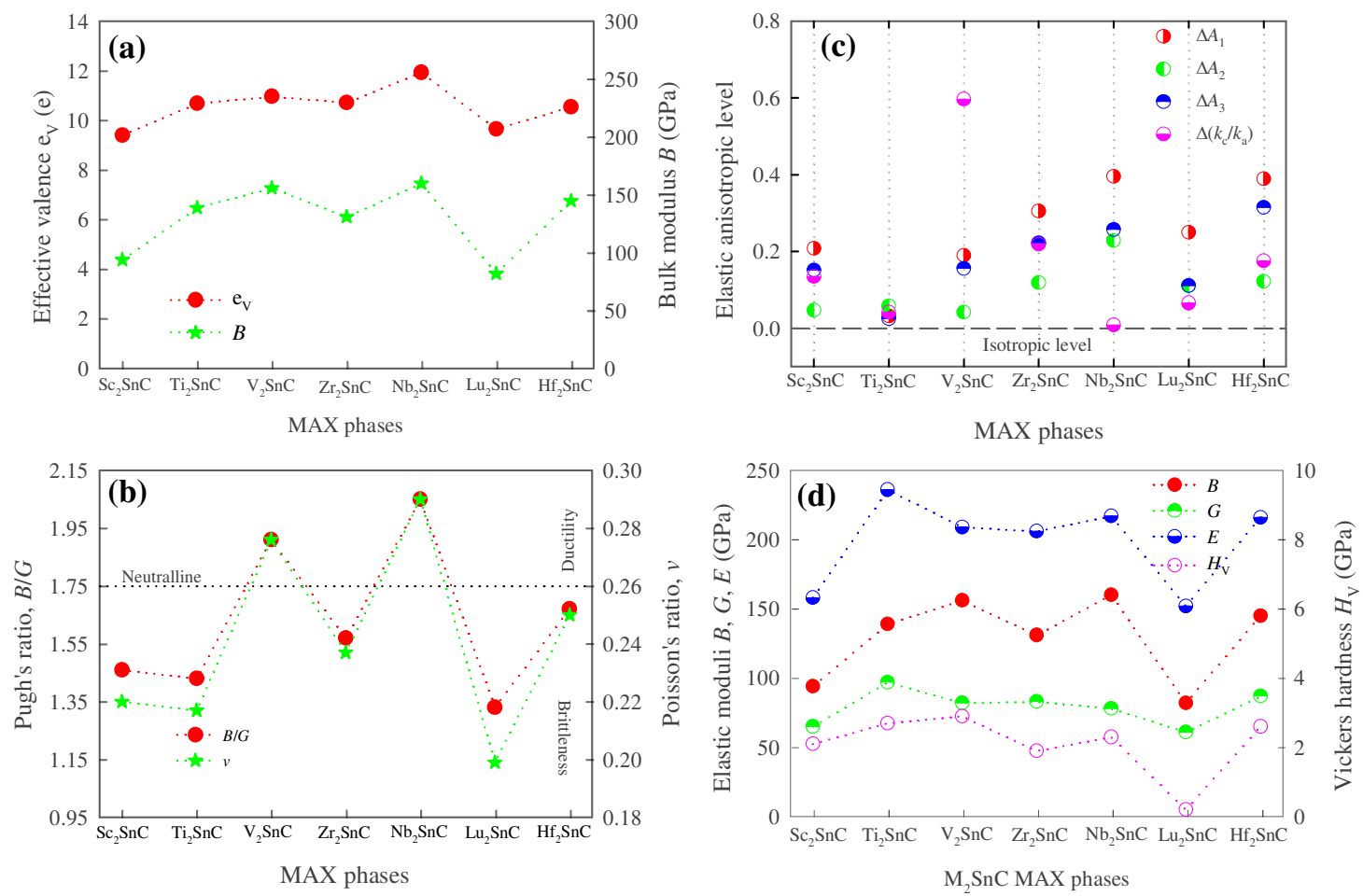

Figure 4. (a) Bulk modulus with effective valence; (b) Pugh's and Poisson's ratio; (c) elastic anisotropy level and (d) Vickers hardness with elastic moduli of $\mathrm{M}_{2} \mathrm{SnC}$.

Poisson's ratio $v$ is another important parameter and can be derived from $B$ and $G: v=(3 B-$ $2 G) /(6 B+2 G)$. Similar to Pugh's ratio, Poisson's ratio can serve as a predictor for distinguishing brittle and ductile materials from neutral ones. Poisson's ratio $v$ with a value of 0.26 identifies the neutral materials as well as with a lower value it find outs the brittle materials and with a higher value it seeks the ductile ones ${ }^{41}$. The Poisson's ratio has classified the $\mathrm{M}_{2} \mathrm{SnC}$ MAX phases into brittle and ductile groups, just as the Pugh's ratio has classified them above. That is, the $\mathrm{Sc}_{2} \mathrm{SnC}$ can be considered brittle. The Poisson's ratio can also identify the interatomic forces between atoms in a solid $^{42}$. When the Poisson's ratio of a solid is between $0.25-0.50$, the interatomic forces between the atoms of that solid will be the central forces. If the Poisson's ratio is outside of this range the interatomic forces will be the non-central forces. The Poisson's ratio of $\mathrm{V}_{2} \mathrm{SnC}, \mathrm{Hf}_{2} \mathrm{SnC}$ and $\mathrm{Nb}_{2} \mathrm{SnC}$ lies in this range and accordingly their interatomic forces are central forces. The interatomic forces in the new phase $\mathrm{Sc}_{2} \mathrm{SnC}$ including remaining $\mathrm{M}_{2} \mathrm{SnC}$ phases are non-central forces as their Poisson's ratios are outside this range. Moreover, the Poisson's ratio can predict the bonding nature in solids ${ }^{43}$. A completely covalent crystal is characterized with a Poisson's ratio equal or less than 0.1 . A perfectly metallic compound possesses a Poisson's ratio equal or greater than 0.33 . The Poisson's ratio of $\mathrm{Sc}_{2} \mathrm{SnC}$ including existing $\mathrm{M}_{2} \mathrm{SnC}$ lies between 0.1 and 0.33 , indicating that their chemical bonding is a combination of metallic and covalent natures.

Elastic moduli $B$ and $G$ also provide another essential property; the Young's modulus $E$ through the equation, $E=9 B G /(3 B+G)$. The Young's modulus of a material is a useful property for predicting the behaviour of the material when subjected to a tensile force. Stiffness of a material mostly depends on its Young's modulus. Higher Young's modulus is an indication of higher stiffness. In the family of $\mathrm{M}_{2} \mathrm{SnC} M A X$ phases, $\mathrm{Ti}_{2} \mathrm{SnC}$ is the stiffest material and $\mathrm{Lu}_{2} \mathrm{SnC}$ is the softest one. The newly synthesized $\mathrm{Sc}_{2} \mathrm{SnC}$ ranks second on the scale of softness: $\mathrm{Lu}_{2} \mathrm{SnC}>\mathrm{Sc}_{2} \mathrm{SnC}>\mathrm{Nb}_{2} \mathrm{SnC}>\mathrm{Zr}_{2} \mathrm{SnC}>\mathrm{V}_{2} \mathrm{SnC}$ $>\mathrm{Hf}_{2} \mathrm{SnC}>\mathrm{Ti}_{2} \mathrm{SnC}$. Again, the larger the $E$ value, the greater the exfoliation energy. Among the effectively etched MAX phases into 2D MXenes, $V_{2} A I C$ has the largest exfoliation energy, whose $E$ is reported to be 311 and $316 \mathrm{GPa}^{44,45}$. In view of that, the exfoliation energy of newly synthesized 
$\mathrm{Sc}_{2} \mathrm{SnC}$ and other $\mathrm{M}_{2} \mathrm{SnC}$ phases have lower exfoliation energy than $\mathrm{V}_{2} \mathrm{AlC}$. Therefore, $\mathrm{Sc}_{2} \mathrm{SnC}$ and other $\mathrm{M}_{2} \mathrm{SnC}$ phases are more likely to be etched into 2D MXenes than $\mathrm{V}_{2} \mathrm{AlC}$. Further, the Young's modulus $E$ has a good relation to the thermal shock resistance $R: R \propto 1 / E^{46}$. The lower the Young's modulus, the better the thermal shock resistance. A material of higher thermal shock resistance (i.e., lower Young's modulus) has the potential to be used as a thermal barrier coating (TBC) material. The Young's modulus of newly synthesized $\mathrm{Sc}_{2} \mathrm{SnC}$ and other $\mathrm{M}_{2} \mathrm{SnC}$ MAX phases are lower than that of a potential TBC material $\mathrm{TiO}_{2}$ whose Young modulus is $283 \mathrm{GPa}^{47}$. Therefore, $\mathrm{Sc}_{2} \mathrm{SnC}$ and other existing $\mathrm{M}_{2} \mathrm{SnC}$ phases have possibility to be TBC materials if they also have high thermal expansion coefficient and melting point, low thermal conductivity, and good oxidation resistance.

Elastic anisotropy: The study of elastic anisotropy is important in materials science as it influences a variety of physical processes including the development of plastic deformation in crystals, microscale cracking in ceramics, and plastic relaxation in thin-film metallics ${ }^{48}$. For hexagonal crystals like MAX phases the shear anisotropy factors $A_{i}(i=1,2,3)$ are studied extensively ${ }^{21,22,25,31,49}$. The equation that determines the shear anisotropy factor $A_{1}$, for the $\{100\}$ shear planes between the $\langle 011\rangle$ and $<010>$ directions, is $A_{1}=\left(C_{11}+C_{12}+2 C_{33}-4 C_{12}\right) / 6 C_{44}$; the equation of $A_{2}$, for the $\{010\}$ shear planes between $<101>$ and $<001>$ directions, is $A_{2}=2 C_{44} /\left(C_{11}-C_{12}\right)$; and the equation of $A_{3}$, for the $\{001\}$ shear planes between $\langle 110\rangle$ and $\langle 010\rangle$ directions, is $A_{3}=\left(C_{11}+C_{12}+2 C_{33}-4 C_{13}\right) / 3\left(C_{11}-C_{12}\right)$. Deviation of $A_{\mathrm{i}}$ from unity $\Delta A_{\mathrm{i}}\left(=A_{\mathrm{i}} \sim 1\right)$ quantifies the degree of the shear anisotropy of crystals. The calculated $A_{i}$ is listed in Table $S 4$ and the anisotropy level $\Delta A_{i}$ is shown in Figure $4 \mathrm{c}$. Considering the average on the all planes, $\mathrm{Ti}_{2} \mathrm{SnC}$ is elastically less anisotropic and $\mathrm{Nb}_{2} \mathrm{SnC}$ is elastically highly anisotropic. $\mathrm{Sc}_{2} \mathrm{SnC}$ ranks third in view of less anisotropy in the $\mathrm{M}_{2} \mathrm{SnC}$ family: $\mathrm{Nb}_{2} \mathrm{SnC}>\mathrm{Hf}_{2} \mathrm{SnC}>$ $\mathrm{Zr}_{2} \mathrm{SnC}>\mathrm{Lu}_{2} \mathrm{SnC}>\mathrm{Sc}_{2} \mathrm{SnC}>\mathrm{V}_{2} \mathrm{SnC}>\mathrm{Ti}_{2} \mathrm{SnC}$. Individually, in the $\{100\}$ shear planes $\mathrm{Nb}_{2} \mathrm{SnC}$ is highly anisotropic; in the $\{010\}$ shear planes $\mathrm{Nb}_{2} \mathrm{SnC}$ is again highly anisotropic and in the $\{001\}$ shear planes $\mathrm{Hf}_{2} \mathrm{SnC}$ is highly anisotropic.

The anisotropy level in the hexagonal crystals like MAX phases can also be quantified by another anisotropy factor named compressibility anisotropy factor and it is defined as $k_{\mathrm{c}} / k_{\mathrm{a}}=\left(C_{11}+C_{12}-\right.$ $\left.2 C_{13}\right) /\left(C_{33}-C_{13}\right)^{41}$. Here, $k_{\mathrm{a}}$ and $k_{\mathrm{c}}$ are the linear compressibility coefficients along the $a$ - and c-axis, respectively. Deviation of $k_{c} / k_{\mathrm{a}}$ from the unity $\Delta\left(k_{\mathrm{c}} / k_{\mathrm{a}}\right)\left(=k_{\mathrm{c}} / k_{\mathrm{a}} \sim 1\right)$ quantifies the degree of the compressibility anisotropy of crystals. The calculated $k_{\mathrm{c}} / k_{\mathrm{a}}$ is listed in Table $\mathrm{S} 4$ and $\Delta\left(k_{\mathrm{c}} / k_{\mathrm{a}}\right)$ is shown in Fig. 4c. The compressibility anisotropy level is highest in $\mathrm{V}_{2} \mathrm{SnC}$ and lowest in $\mathrm{Nb}_{2} \mathrm{SnC}$. $\mathrm{Sc}_{2} \mathrm{SnC}$ ranks in the middle in the $\mathrm{M}_{2} \mathrm{SnC}$ family of seven members. If $k_{c} / k_{\mathrm{a}}>1$, the material is more compressible along the c-axis than along the a-axis. Therefore, $\mathrm{Sc}_{2} \mathrm{SnC}, \mathrm{Ti}_{2} \mathrm{SnC}$ and $\mathrm{Lu}_{2} \mathrm{SnC}$ are slightly more compressible along the c-axis than along the a-axis while $\mathrm{V}_{2} \mathrm{SnC}, \mathrm{Zr}_{2} \mathrm{SnC}, \mathrm{Nb}_{2} \mathrm{SnC}$ and $\mathrm{Hf}_{2} \mathrm{SnC}$ are compressed more easily along the a-axis than along the c-axis.

There are some anisotropy factors such as percentage anisotropy factors $A_{\mathrm{B} \%}$ and $A_{G \%}$ based on the bulk and shear moduli within the Voigt and Reuss limits, which are applicable for all types of crystals. $A_{\mathrm{B} \%}$ measures anisotropy in compression while $A_{\mathrm{G}}$ measures anisotropy in shear. These two factors are defined as $A_{B} \%=\left[\left(B_{V}-B_{R}\right) /\left(B_{V}+B_{R}\right)\right] \times 100 \%$ and $A_{G \%}=\left[\left(G_{V}-G_{R}\right) /\left(G_{V}+G_{R}\right)\right] \times 100 \%{ }^{43}$. The calculated values are listed in Table 54 . Both these factors assign zero value for isotropic crystals and their positive values indicate the anisotropy level in crystals. $A_{B}$ is highest for $\mathrm{V}_{2} \mathrm{SnC}$ and lowest for $\mathrm{Ti}_{2} \mathrm{SnC}$ while $A_{\mathrm{G}}$ is highest for $\mathrm{Hf}_{2} \mathrm{SnC}$ and lowest for $\mathrm{Ti}_{2} \mathrm{SnC}$. $\mathrm{Sc}_{2} \mathrm{SnC}$ ranks fourth on the $A_{B} \%$ scale and second on the $A_{G \%}$ scale in terms of minimum anisotropy. Universal anisotropy factor $A^{\mathrm{U}}$ is also applicable for all types of crystals. It is defined as $A^{\mathrm{U}}=5\left(G_{v} / G_{R}\right)+\left(B_{v} / B_{R}\right)-6 \geq 0^{30}$. Its zero value corresponds to isotropic crystals and a positive value implies the anisotropy level in crystals. The calculated values are listed in Table $\mathrm{S} 4$. $\mathrm{Hf}_{2} \mathrm{SnC}$ has the highest value of $A^{\mathrm{U}}$ and $\mathrm{Ti}_{2} \mathrm{SnC}$ possesses the lowest value. $\mathrm{Sc}_{2} \mathrm{SnC}$ has the second lowest value of $A^{\mathrm{U}}$.

The $2 \mathrm{D}$ and $3 \mathrm{D}$ graphical representations of the directional elastic properties of materials are visualization of elastic anisotropy in crystals. ELATE is open-source software ${ }^{50}$, which allows the direct visualization of anisotropy level in Young's modulus $(E)$, linear compressibility $(\beta)$, shear modulus $(G)$ and Poisson's ratio $(v)$ on the 3D spherical plot, as well as 2D projections on the (xy), (xz) and $(\mathrm{yz})$ planes. Uniform circular 2D and spherical 3D graphical representations are the indications of 
isotropic nature of crystals. Above, it is predicted that the hexagonal crystals like MAX phases are elastically isotropic in the xy plane. It is evident that the $2 \mathrm{D}$ presentation of $E, B, G$ and $v$ of $\mathrm{Sc}_{2} \mathrm{SnC}$ in the $x y$ plane in Fig. 5 are uniformly circular, indicating the isotropic nature of elastic properties of $\mathrm{Sc}_{2} \mathrm{SnC}$ in xy plane. The $2 \mathrm{D}$ presentation of $E, 6, G$ and $v$ of $\mathrm{Sc}_{2} \mathrm{SnC}$ in the $\mathrm{xz}$ and yz planes in Fig. 5 is indicating the elastic anisotropy of $\mathrm{Sc}_{2} \mathrm{SnC}$ in those planes. The greater the deviation from the round shape, the higher the anisotropy level in the crystals in that plane.
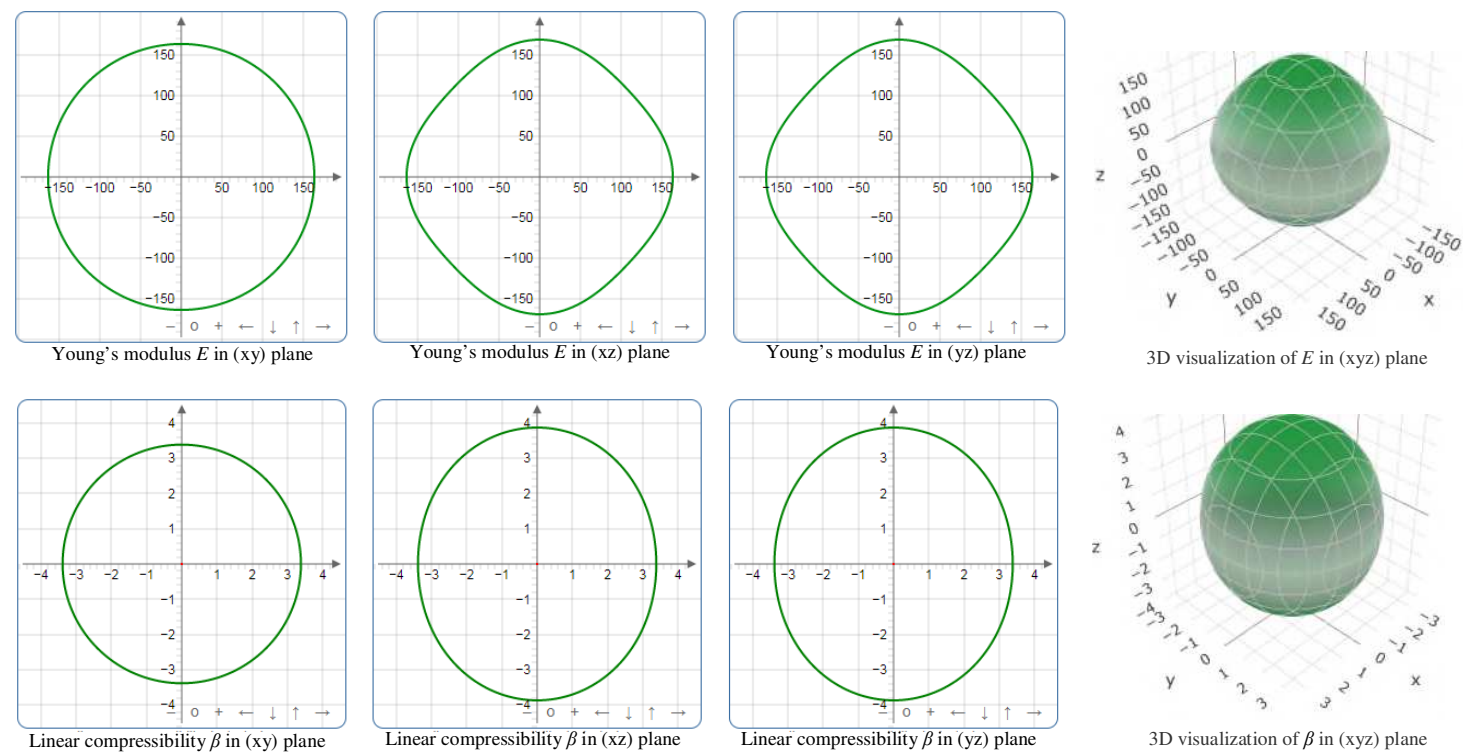

3D visualization of $E$ in (xyz) plane
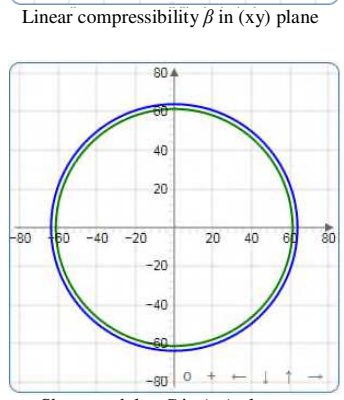

Shear modulus $G$ in (xy) plane

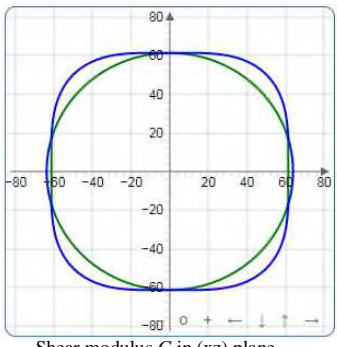

Shear modulus $G$ in (xz) plane
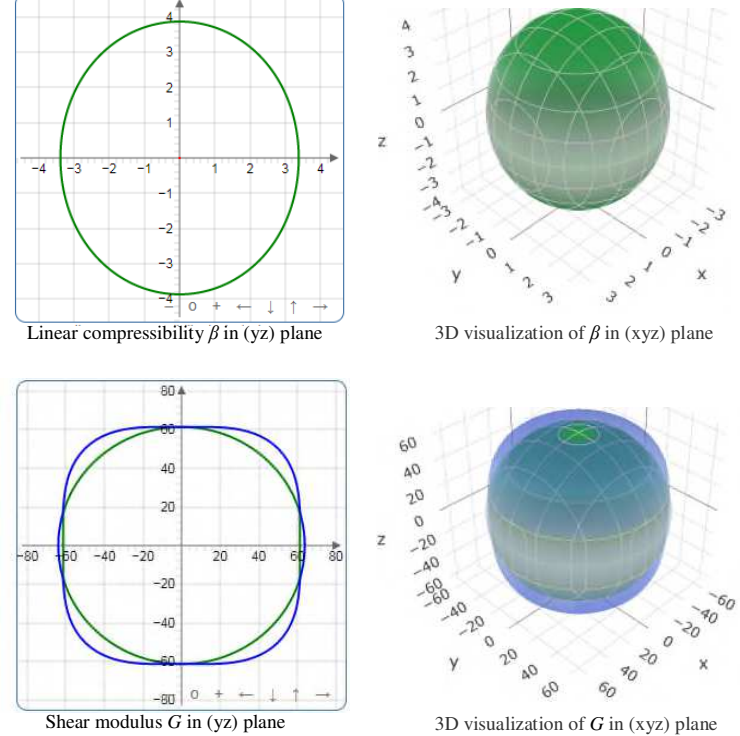

3D visualization of $\beta$ in (xyz) plane
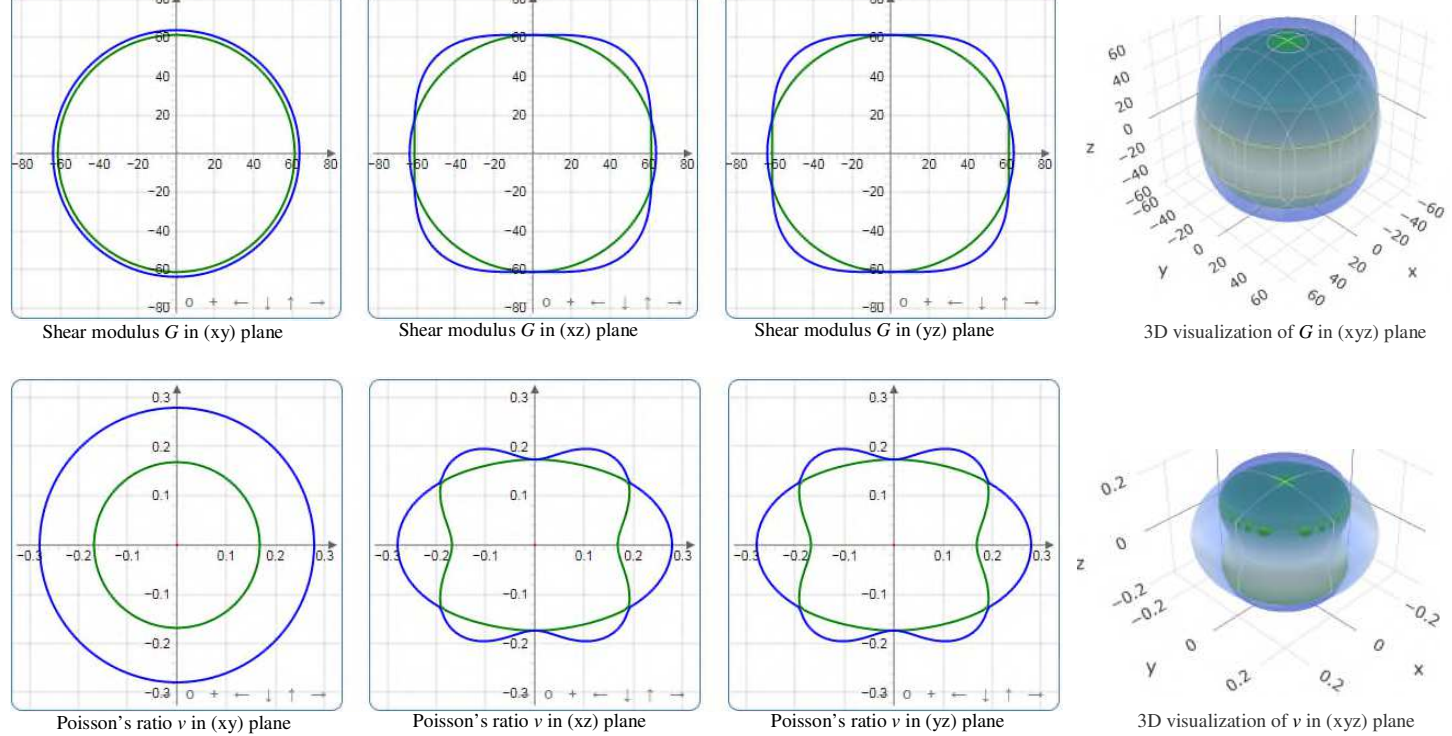

3D visualization of $G$ in (xyz) plane

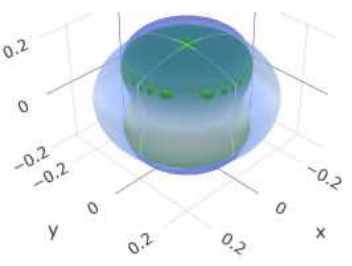

3D visualization of $v$ in (xyz) plane

Figure 5. Directional dependence of Young's modulus $(E)$, linear compressibility $(B)$, shear modulus $(G)$ and Poisson's ratio $(v)$ of $\mathrm{Sc}_{2} \mathrm{SnC}$.

In 2D and 3D presentations, ELATE uses maximum two colours for $E$ and $\beta$ and maximum three colors for $G$ and $v$. The $E$ and $\beta$ are functions of a single unit vector $\mathbf{a}(\vartheta, \phi)$ while $G$ and $v$ depend on two orthogonal unit vectors $\mathbf{a}(\vartheta, \phi)$ and $\mathbf{b}(\vartheta, \phi, \chi)$ (a in the direction of the stress applied while $\mathbf{b}$ in the direction of measurement). The spherical coordinates $\vartheta, \phi$, and $\chi$ can be defined as $0 \leqslant \vartheta \leqslant \pi, 0$ $\leqslant \phi \leqslant 2 \pi$, and $0 \leqslant \chi \leqslant 2 \pi$. Therefore, $E, \beta, G$ and $v$ can be expressed as $E(\vartheta, \phi), \beta(\vartheta, \phi), G(\vartheta, \phi, \chi)$ and $v(\vartheta, \phi, \chi) . G(\vartheta, \phi, \chi)$ and $v(\vartheta, \phi, \chi)$ are represented in 3D space via plotting two surfaces $f$ and $g$ 
each with the spherical $(\vartheta, \phi)$ coordinates. The surfaces $f$ and $g$ represent the minimal and maximal values over all possible values of $\chi: f(\vartheta, \phi)=\min _{\chi} X(\vartheta, \phi, \chi)$ and $g(\vartheta, \phi)=\max _{\chi} X(\vartheta, \phi, \chi)$,

respectively. The surface $g$ encloses the surface $f$. For this reason, $g$ is plotted in translucent blue colour in Fig. 5. The surface $f$ is represented with solid green color for positive values and translucent red color for negative values. The absence of red color implies that there are no negative values for $E, \beta, G$ and $v$ of $\mathrm{Sc}_{2} \mathrm{SnC}$ in any directions. The directional dependencies of $E, \beta, G$ and $v$ on the $\mathrm{xz}$ and yz planes are almost identical for $\mathrm{Sc}_{2} \mathrm{SnC}$, similar to $\mathrm{Nb}_{2} \mathrm{SnC}, \mathrm{Hf}_{2} \mathrm{SnC}$ and $\mathrm{Zr}_{2} \mathrm{SnC}$ MAX phases ${ }^{30}$. $\mathrm{Ti}_{2} \mathrm{SnC}$ displays almost isotropic nature of $E, \beta, G$ and $v$ in the $x z$ and yz planes. The directional dependence of $E, \beta, G$, and $v$ in the $\mathrm{Lu}_{2} \mathrm{SnC}$ differs from that of other $\mathrm{M}_{2} \mathrm{SnC}$ phases. For $\mathrm{Sc}_{2} \mathrm{SnC}, \mathrm{Ti}_{2} \mathrm{SnC}$ and $\mathrm{Lu}_{2} \mathrm{SnC}, \beta$ has almost no directional dependence.

ELATE imparts a quantitative analysis reporting the minimum and maximum values of each modulus along with the directions along which these extrema occur. It also allows determining the directions of special interest for elastic properties, which are not required to be along the crystallographic axes of the material. Additionally, it reports a measurement of the anisotropy $A_{x}$ of each elastic modulus $X$, which is defined below:

$A_{X}=\left\{\begin{array}{l}X_{\max } / X_{\min } \\ \infty \text { otherwise }\end{array}\right.$ if $\operatorname{sign}\left(X_{\max }\right)=\operatorname{sign}\left(X_{\min }\right)$

The results are listed in Table 1. It is evident that Young's modulus exhibits maximum anisotropy for $\mathrm{Nb}_{2} \mathrm{SnC}$ and minimum for $\mathrm{Ti}_{2} \mathrm{SnC}$ and $\mathrm{Sc}_{2} \mathrm{SnC}$ ranks second in view of minimum anisotropy.

Anisotropy in linear compressibility is maximum for $\mathrm{V}_{2} \mathrm{SnC}$ and minimum for $\mathrm{Ti}_{2} \mathrm{SnC}_{3} \mathrm{Sc}_{2} \mathrm{SnC}_{\text {ranks }}$ third in scale of minimum anisotropy. Anisotropy in shear modulus is highest for $\mathrm{Hf}_{2} \mathrm{SnC}$ and lowest for $\mathrm{Ti}_{2} \mathrm{SnC} ; \mathrm{Sc}_{2} \mathrm{SnC}$ ranks second in view of minimum anisotropy. Maximum anisotropy of Poisson's ratio is observed in $\mathrm{Hf}_{2} \mathrm{SnC}$ and minimum in $\mathrm{Ti}_{2} \mathrm{SnC}$, whereas $\mathrm{Sc}_{2} \mathrm{SnC}$ ranks third in view of minimum anisotropy. The lowest anisotropy is observed for $\mathrm{Ti}_{2} \mathrm{SnC}$ in the $\mathrm{M}_{2} \mathrm{SnC}$ family considering all indicators.

Table 1. Minimal and maximal values of each modulus and elastic anisotropy of $\mathrm{Sc}_{2} \mathrm{SnC}$ and existing $\mathrm{M}_{2} \mathrm{SnC}^{30,31}$.

\begin{tabular}{|c|c|c|c|c|c|c|c|c|}
\hline \multirow[t]{2}{*}{ Phases } & \multicolumn{2}{|c|}{$\begin{array}{l}\text { Young's modulus } \\
\text { (GPa) }\end{array}$} & \multicolumn{2}{|c|}{$\begin{array}{l}\text { Linear compressibility } \\
\left(\mathrm{TPa}^{-1}\right)\end{array}$} & \multicolumn{2}{|c|}{ Shear modulus (GPa) } & \multicolumn{2}{|c|}{ Poisson's ratio } \\
\hline & $E_{\min }$ & $E_{\max }$ & $B_{\min }$ & $B_{\max }$ & $G_{\min }$ & $G_{\max }$ & $v_{\min }$ & $v_{\max }$ \\
\hline $\mathrm{Sc}_{2} \mathrm{SnC}$ & 152.13 & 168.70 & 3.383 & 3.868 & 61.388 & 70.888 & 0.174 & 0.279 \\
\hline $\mathrm{V}_{2} \mathrm{SnC}$ & 188.79 & 223.85 & 1.096 & 2.711 & 71.355 & 86.673 & 0.129 & 0.388 \\
\hline $\mathrm{Hf}_{2} \mathrm{SnC}$ & 168.97 & 236.44 & 1.958 & 2.481 & 66.846 & 99.802 & 0.122 & 0.390 \\
\hline $\mathrm{Lu}_{2} \mathrm{SnC}$ & 143.59 & 167.39 & 3.831 & 3.959 & 56.841 & 70.092 & 0.166 & 0.264 \\
\hline $\mathrm{Nb}_{2} \mathrm{SnC}$ & 168.47 & 237.13 & 1.778 & 2.149 & 66.303 & 97.202 & 0.153 & 0.417 \\
\hline $\mathrm{Ti}_{2} \mathrm{SnC}$ & 233.72 & 239.43 & 2.415 & 2.451 & 95.408 & 100.210 & 0.194 & 0.225 \\
\hline $\mathrm{Zr}_{2} \mathrm{SnC}$ & 174.63 & 222.77 & 2.140 & 2.789 & 68.418 & 94.736 & 0.136 & 0.338 \\
\hline \multicolumn{9}{|c|}{ Elastic anisotropy $A_{x}$} \\
\hline & \multicolumn{2}{|c|}{$A_{E}$} & \multicolumn{2}{|c|}{$A_{6}$} & \multicolumn{2}{|c|}{$A_{G}$} & \multicolumn{2}{|c|}{$A_{v}$} \\
\hline $\mathrm{Sc}_{2} \mathrm{SnC}$ & \multicolumn{2}{|c|}{1.109} & \multicolumn{2}{|c|}{1.143} & \multicolumn{2}{|c|}{1.155} & \multicolumn{2}{|c|}{1.605} \\
\hline $\mathrm{V}_{2} \mathrm{SnC}$ & \multicolumn{2}{|c|}{1.186} & \multicolumn{2}{|c|}{2.473} & \multicolumn{2}{|c|}{1.215} & \multicolumn{2}{|c|}{3.022} \\
\hline $\mathrm{Hf}_{2} \mathrm{SnC}$ & \multicolumn{2}{|c|}{1.399} & \multicolumn{2}{|c|}{1.267} & \multicolumn{2}{|c|}{1.493} & \multicolumn{2}{|c|}{3.195} \\
\hline $\mathrm{Lu}_{2} \mathrm{SnC}$ & \multicolumn{2}{|c|}{1.166} & \multicolumn{2}{|c|}{1.033} & \multicolumn{2}{|c|}{1.233} & \multicolumn{2}{|c|}{1.589} \\
\hline $\mathrm{Nb}_{2} \mathrm{SnC}$ & \multicolumn{2}{|c|}{1.408} & \multicolumn{2}{|c|}{1.208} & \multicolumn{2}{|c|}{1.466} & \multicolumn{2}{|c|}{2.730} \\
\hline $\mathrm{Ti}_{2} \mathrm{SnC}$ & \multicolumn{2}{|c|}{1.024} & \multicolumn{2}{|c|}{1.015} & \multicolumn{2}{|c|}{1.050} & \multicolumn{2}{|c|}{1.159} \\
\hline $\mathrm{Zr}_{2} \mathrm{SnC}$ & \multicolumn{2}{|c|}{1.276} & \multicolumn{2}{|c|}{1.303} & & & & \\
\hline
\end{tabular}

Theoretical hardness: Hardness is the property of a material that facilitates it to resist plastic deformation, penetration, indentation and scratching. Therefore, hardness is important from an 
engineering point of view because the resistance to wear by either abrasion or corrosion by steam, oil and water usually increases with hardness. Theoretical modeling for hardness calculation of partially metallic compounds like ternary MAX phases is difficult. Gou et al. developed a mode $\left.\right|^{51}$ based on Mulliken bond population ${ }^{34}$ that is able to calculate the theoretical Vickers hardness of MAX phases. According to this model the bond hardness can be calculated as:

$H_{v}^{\mu}=740\left(P^{\mu}-P^{\mu \prime}\right)\left(v_{b}^{\mu}\right)^{-5 / 3}$

where $P^{\mu}$ denotes to the positive Mulliken bond overlap population of the $\mu$-type bond, $P^{\mu \prime}$ represents the metallic population that is derived from the unit cell volume $V$ and the number of free electrons in the cell, $n_{\text {free }}$ with the formula, $P^{\mu \prime}=\frac{n_{\text {free }}}{V}$, here $n_{\text {free }}=\int_{E_{P}}^{E_{F}} N(E) d E$ and $E_{\mathrm{p}}$ and $E_{\mathrm{F}}$ define the energy at the pseudogap and at the Fermi level, respectively, and $v_{b}^{\mu}$ is the bond volume of a $\mu$-type bond calculated using the equation $v_{b}^{\mu}=\left(d^{\mu}\right)^{3} / \sum_{\mu}\left[\left(d^{\mu}\right)^{3} N_{b}^{\mu}\right]$, here $d^{\mu}$ and $N_{b}^{\mu}$ are respectively the bond length and bond number of $\mu$ type bonds per unit volume.

When a compound has a positive bond population for multiple bonds, the following equation is used to calculate its Vickers hardness:

$$
H_{V}=\left[\stackrel{\mu}{\Pi}\left(H_{v}^{\mu}\right)^{n^{\mu}}\right]^{1 / \Sigma n^{\mu}}
$$

where $n^{\mu}$ represents the number of $\mu$-type bonds. Table $\mathrm{S} 5$ lists the Vickers hardness of $\mathrm{Sc}_{2} \mathrm{SnC}_{\mathrm{N}}$ and other $\mathrm{M}_{2} \mathrm{SnC}$ MAX phases. $\mathrm{Sc}_{2} \mathrm{SnC}$ is harder than $\mathrm{Lu}_{2} \mathrm{SnC}$ and $\mathrm{Zr}_{2} \mathrm{SnC}$ and softer than $\mathrm{Ti}_{2} \mathrm{SnC}, \mathrm{V}_{2} \mathrm{SnC}$, $\mathrm{Nb}_{2} \mathrm{SnC}$ and $\mathrm{Hf}_{2} \mathrm{SnC}$. We have found two sets of experimental Vickers hardness for $\mathrm{Ti}_{2} \mathrm{SnC}, \mathrm{Zr}_{2} \mathrm{SnC}$, $\mathrm{Hf}_{2} \mathrm{SnC}$, and $\mathrm{Nb}_{2} \mathrm{SnC}^{32,52}$. Experimental values show deviations from one set to another except for $\mathrm{Ti}_{2} \mathrm{SnC}$. This can be due to sample purity and errors induced by the instruments. The experimental temperature may be another reason. Although the theoretical values deviate from the experimental values they remain within the typical values $(2-8 \mathrm{GPa})$ for MAX phases. $\mathrm{Lu}_{2} \mathrm{SnC}$ has a low value for $H_{v}$, which is very small compared to the lower limit (2 GPa) for the MAX phases. The reason may be the absence of covalent $\mathrm{M}-\mathrm{C}$ bond in $\mathrm{Lu}_{2} \mathrm{SnC}$. Indeed, all $\mathrm{M}_{2} \mathrm{SnC}$ phases have low hardness compared to most of the MAX phases. Consequently, $\mathrm{M}_{2} \mathrm{SnC}$ phases are easily machinable compared to other MAX phases.

In general, the hardness of a compound has a better relationship with its shear and Young's modulus than bulk modulus ${ }^{3}$. We have plotted the Vickers hardness of $\mathrm{M}_{2} \mathrm{SnC}$ MAX phases in Fig. $4 \mathrm{~d}$ along with their elastic moduli. For the $\mathrm{M}_{2} \mathrm{SnC}$ MAX phases, it is observed that the hardness follows the trend of bulk modulus instead of shear and Young's modulus. Further verification is needed to determine whether this trend continues for the carbide MAX phase with a specific A-group element.

\section{Lattice dynamics:}

The subject of lattice dynamics is the study of the vibrations of the atoms in a crystal. The vibrations of the atoms are related to many important physical properties such as lattice thermal conductivity, minimum thermal conductivity, Debye temperature, melting point, phonon dispersion, phonon DOS etc. These properties are investigated for newly synthesized $\mathrm{Sc}_{2} \mathrm{SnC}$ to compare with existing $\mathrm{M}_{2} \mathrm{SnC}$ phases

Debye temperature: Debye temperature is a characteristic temperature at which the highestfrequency mode (and hence every possible mode) is excited. It is related to many physical properties such as thermal expansion, thermal conductivity, specific heat and lattice enthalpy. Anderson method is simple and rigorous for calculating the Debye temperature of crystalline materials and uses the following equation ${ }^{53}$ :

$\theta_{\mathrm{D}}=\frac{h}{k_{\mathrm{B}}}\left[\left(\frac{3 n}{4 \pi}\right) \frac{N_{\mathrm{A}} \rho}{M}\right]^{1 / 3} v_{\mathrm{m}}$ 
All symbols bear the traditional meanings and $v_{m}$ refers to the average sound velocity, which can be determined using the following equation:

$v_{\mathrm{m}}=\left[\frac{1}{3}\left(\frac{1}{v_{1}^{3}}+\frac{2}{v_{\mathrm{t}}^{3}}\right)\right]^{-1 / 3}$

Here, $v_{l}$ and $v_{t}$ are the longitudinal and transverse sound velocities, respectively. They can be calculated from the bulk and shear moduli $B$ and $G$ using the equations:

$v_{1}=\left(\frac{3 B+4 G}{3 \rho}\right)^{1 / 2} \quad$ and $\quad v_{\mathrm{t}}=\left(\frac{G}{\rho}\right)^{1 / 2}$

The calculated values of $\vartheta_{D}$ for $\mathrm{M}_{2} \mathrm{SnC}$ MAX phases are listed in Table S6 along with the relevant quantities. The Debye temperature of $\mathrm{Sc}_{2} \mathrm{SnC}$ is the third highest in the $\mathrm{M}_{2} \mathrm{SnC}$ family. In this family, $\mathrm{Ti}_{2} \mathrm{SnC}$ possesses the highest Debye temperature and $\mathrm{Lu}_{2} \mathrm{SnC}$ has the lowest Debye temperature. The Debye temperature of $\mathrm{M}_{2} \mathrm{SnC}$ phases largely depends on the sound velocities and follows the trend of change of sound velocities with the transition metal M (refer to Fig. 6a).
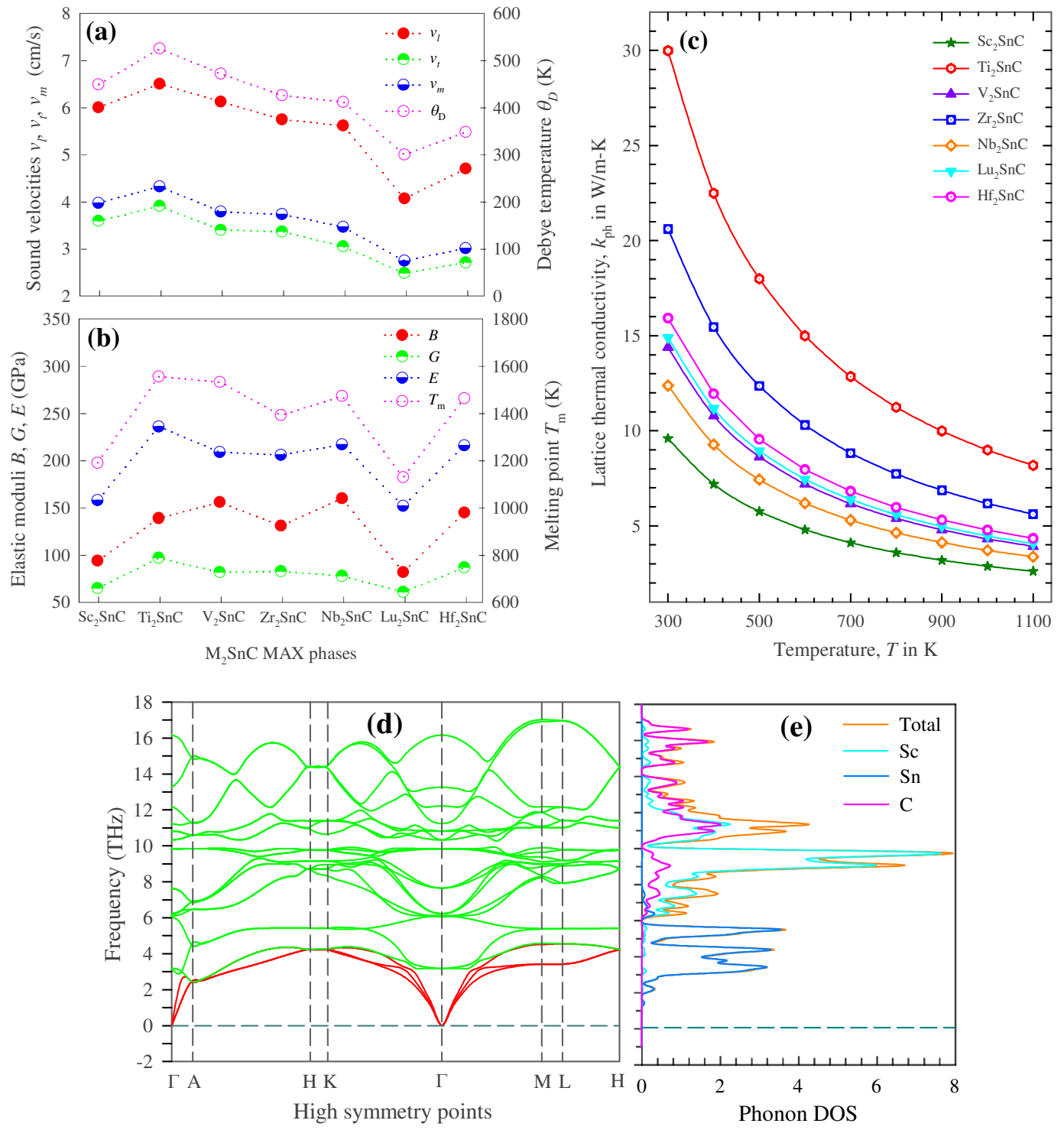

Figure 6. (a) Debye temperature with sound velocities; (b) melting temperature with elastic moduli;

(c) lattice thermal conductivity as function of temperature; (d) phonon dispersion and (e) Phonon DOS. 
Melting point: Melting point of hexagonal crystals like MAX phases can be calculated from elastic constants using: $T_{\mathrm{m}}=354+1.5\left(2 C_{11}+C_{33}\right)^{54}$. The calculated values are listed in Table S6. The new phase $\mathrm{Sc}_{2} \mathrm{SnC}$ possesses the second lowest melting point. The highest melting point is obtained for $\mathrm{Ti}_{2} \mathrm{SnC}$ and the lowest melting point is observed for $\mathrm{Lu}_{2} \mathrm{SnC}$. A higher melting point indicates greater interatomic forces in crystals. Interatomic forces mostly control the bulk elastic properties of crystalline solids. Thus, a relationship can exist between the elastic modulus and the melting temperature of the crystals. Considering this we plotted the elastic moduli and the melting point of $\mathrm{M}_{2} \mathrm{SnC}$ MAX phases in Fig. $6(\mathrm{~b})$. It is observed that the melting point has better correlation with bulk modulus $B$ and Young's modulus $E$ than shear modulus $G$.

Lattice thermal conductivity: The lattice thermal conductivity arises from contributions by phonons of all frequencies. The knowledge of lattice thermal conductivity is important to determine the applicability of a material for use in high temperature environments. Here, the Slack model is used to calculate the lattice thermal conductivity of $\mathrm{Sc}_{2} \mathrm{SnC}$ as MAX phases have dual characteristics of metals and ceramics ${ }^{55}$. The following equation is used in this model:

$k_{\mathrm{ph}}=A \frac{M_{\mathrm{av}} \theta_{D}^{3} \delta}{\gamma^{2} n^{2 / 3} T}$.

The details of this model are found in a recent literature ${ }^{56}$. The room temperature lattice thermal conductivity of $\mathrm{Sc}_{2} \mathrm{SnC}$ and other $\mathrm{M}_{2} \mathrm{SnC}$ phases are listed in Table $\mathrm{S} 6$ and their temperature dependency is shown in Fig. 6(c). It is observed that the new phase $\mathrm{Sc}_{2} \mathrm{SnC}$ has the lowest lattice thermal conductivity in the entire temperature range and $\mathrm{Ti}_{2} \mathrm{SnC}$ possesses the highest values for lattice thermal conductivity. The lattice thermal conductivity of $\mathrm{M}_{2} \mathrm{SnC} \mathrm{MAX}$ phases decrease gradually with the increase of temperature. The rate of decrease is slower for the $\mathrm{Sc}_{2} \mathrm{SnC}_{\mathrm{C}}$ phase and faster for the $\mathrm{Ti}_{2} \mathrm{SnC}$ phase. $\mathrm{Sc}_{2} \mathrm{SnC}$ should be most suitable candidate for thermal barrier coating (TBC) material due to its low lattice thermal conductivity.

Minimum thermal conductivity: Thermal conductivity decreases with increasing temperature. Thus, the minimum value of thermal conductivity is significant for the application of materials at high temperature conditions, for instance, materials selection and design for thermoelectric, thermal barrier coating and other thermal management applications. The concept of a minimum thermal conductivity, $\kappa_{\mathrm{min}}$, carried by the atomic vibrations of any solid material leads to development of different models to determine it. Clarke model has become popular for determining the minimum thermal conductivity of solids via the equation ${ }^{57}$ :

$\kappa_{\min }=k_{\mathrm{B}} v_{\mathrm{m}}\left(\frac{n N_{\mathrm{A}} \rho}{M}\right)^{2 / 3}$

All symbols in equation (11) are consistent to the symbols used in equation (7). The calculated value of $\kappa_{\min }$ is listed in Table S6. The phase $\mathrm{Sc}_{2} \mathrm{SnC}$ has the third highest value for $\kappa_{\min }$. The highest value is found for $\mathrm{V}_{2} \mathrm{SnC}$ and the lowest value is observed for $\mathrm{Lu}_{2} \mathrm{SnC}$. The ultralow minimum thermal conductivity of $1.25 \mathrm{~W} / \mathrm{m}-\mathrm{K}$ is used for screening the appropriate materials for TBC application ${ }^{58}$. The values of $\kappa_{\min }$ for $\mathrm{M}_{2} \mathrm{SnC}$ MAX phases are closer or lower than this optimum value. Therefore, all $\mathrm{M}_{2} \mathrm{SnC}$ phases should be promising TBC materials with greater possibility for $\mathrm{Lu}_{2} \mathrm{SnC}$.

Phonon dispersion and Phonon DOS: It is important to study the phonon dispersion and phonon density of states (DOS) to verify the dynamical stability of the crystalline solids. The calculated phonon dispersion is shown in Figure 6(d). For a dynamically stable crystal, there are always three phonons with zero frequency at $\Gamma$-point, which corresponds to $k=0$ in the reciprocal space. The phonon branches starting at $\omega(k)=0$ are called acoustic phonon dispersion curves. In the case of $\mathrm{Sc}_{2} \mathrm{SnC}$ (refer to Figure $6(\mathrm{~d})$ ) the acoustic branches start at $\omega(k)=0$ and consequently indicates the dynamical stability of $\mathrm{Sc}_{2} \mathrm{SnC}$. Other phonons, whose frequencies are non-zero at the $\Gamma$ point, are called optical phonons. In a number of high-symmetry crystals, and along the high-symmetry 
directions, the atomic vibrations are either polarized along the propagation wave vector $k$, or perpendicular to $k$. Acoustic modes have one longitudinal acoustic (LA) mode, and two transverse acoustic (TA) modes. A crystal consisting of a unit cell of $N$-atoms has $3 N-3$ optical modes. 211 MAX phases have 21 optical modes. In the Fig. 6(d), the acoustic branches are shown with red and optical branches are identified with green.

The calculated phonon DOS of $\mathrm{Sc}_{2} \mathrm{SnC}$ is shown in Figure 6(e), revealing that the acoustic and the lower optical modes arise due to the vibration of heavier Sn-atoms. The middle optical branches arise due to vibration of Sc-atoms. The higher optical branches mostly originate from the vibration of lighter $\mathrm{C}$-atoms. Acoustic phonon is caused by the coherent vibrations of atoms in a lattice outside their equilibrium position. Conversely, the optical phonon is originated due to the out-of-phase oscillation of the atom in the lattice when an atom moves to the left and its neighbor to the right. Most of the optical properties of the crystals are controlled by the optical phonons.

Defect processes: The motivation to examine the point defect processes of materials stems from the fact that they can impact the macroscopic materials properties (i.e. radiation tolerance $)^{59-61}$. In that respect the investigation of point defects in MAX phases is very important as they can be in radiation environments given that they are considered for nuclear applications ${ }^{62-64}$.

Table 2. The defect reaction energies as calculated for $\mathrm{Sc}_{2} \mathrm{SnC}$ and existing $\mathrm{M}_{2} \mathrm{SnC}^{4,30} \mathrm{MAX}$ phases.

\begin{tabular}{|c|c|c|c|c|c|c|c|c|}
\hline & \multirow{2}{*}{$\begin{array}{l}\text { Reaction (V́ denotes } \\
\text { vacancy) }\end{array}$} & \multirow[b]{2}{*}{$\mathrm{Sc}_{2} \mathrm{SnC}$} & \multicolumn{6}{|c|}{ Defect energy (eV) } \\
\hline & & & $\mathrm{V}_{2} \mathrm{SnC}$ & $\mathrm{Lu}_{2} \mathrm{SnC}$ & $\mathrm{Ti}_{2} \mathrm{SnC}$ & $\mathrm{Zr}_{2} \mathrm{SnC}$ & $\mathrm{Hf}_{2} \mathrm{SnC}$ & $\mathrm{Nb}_{2} \mathrm{SnC}$ \\
\hline 1. & $M_{M} \rightarrow V_{M}^{\prime}+M_{i}$ & 7.35 & 6.40 & 6.61 & 8.75 & 8.66 & 9.34 & 8.70 \\
\hline 2. & $\mathrm{Sn}_{\mathrm{Sn}_{n}} \rightarrow \mathrm{V}_{\mathrm{Sn}}+\mathrm{Sn}_{\mathrm{i}}$ & 4.21 & 7.95 & 3.57 & 8.97 & 6.63 & 7.51 & 7.56 \\
\hline 3. & $C_{c} \rightarrow V_{c}^{\prime}+C_{i}$ & 3.33 & 5.12 & 2.23 & 6.10 & 5.34 & 4.68 & 5.18 \\
\hline 4. & $\mathrm{M}_{\mathrm{M}}+\mathrm{Sn}_{\mathrm{Sn}} \rightarrow \mathrm{M}_{\mathrm{Sn}}+\mathrm{Sn}_{\mathrm{M}}$ & 3.98 & 4.67 & 3.67 & 4.92 & 4.83 & 4.72 & 5.12 \\
\hline 5. & $\mathrm{M}_{\mathrm{M}}+\mathrm{C}_{\mathrm{C}} \rightarrow \mathrm{M}_{\mathrm{C}}+\mathrm{C}_{\mathrm{M}}$ & 11.31 & 9.37 & 11.79 & 12.81 & 15.40 & 16.37 & 12.64 \\
\hline 6. & $\mathrm{Sn}_{\mathrm{Sn}}+\mathrm{C}_{\mathrm{C}} \rightarrow \mathrm{Sn}_{\mathrm{C}}+\mathrm{C}_{\mathrm{Sn}}$ & 8.52 & 8.64 & 7.75 & 9.98 & 9.64 & 10.07 & 10.05 \\
\hline 7. & $\mathrm{Sn}_{\mathrm{i}}+\mathrm{V}_{\mathrm{M}}^{\prime} \rightarrow \mathrm{Sn}_{\mathrm{M}}$ & -4.57 & -5.17 & -3.61 & -6.86 & -4.71 & -5.17 & -4.34 \\
\hline 8. & $C_{i}+V_{M}^{\prime} \rightarrow C_{M}$ & -1.65 & -0.80 & -0.13 & -1.07 & 0.12 & 1.47 & -0.48 \\
\hline 9. & $M_{i}+V_{S n}^{\prime} \rightarrow M_{s n}$ & -3.01 & -4.51 & -2.90 & -5.94 & -5.75 & -6.96 & -6.79 \\
\hline 10. & $C_{i}+V_{S n} \rightarrow C_{S n}$ & 1.26 & 0.03 & 1.56 & -0.19 & 0.22 & 0.89 & -0.10 \\
\hline 11. & $M_{i}+V_{C}^{\prime} \rightarrow M_{c}$ & 2.27 & -1.35 & 3.08 & -0.97 & 1.28 & 0.88 & -0.76 \\
\hline 12. & $\mathrm{Sn}_{\mathrm{i}}+\mathrm{V}_{\mathrm{C}} \rightarrow \mathrm{Sn}_{\mathrm{C}}$ & -0.29 & -4.46 & 0.39 & -4.91 & -2.55 & -3.01 & -2.58 \\
\hline 13. & $\mathrm{M}_{\mathrm{i}}+\mathrm{Sn}_{\mathrm{Sn}} \rightarrow \mathrm{M}_{\mathrm{sn}}+\mathrm{Sn}_{\mathrm{i}}$ & 1.20 & 3.44 & 0.67 & 3.03 & 0.88 & 0.55 & 0.76 \\
\hline 14. & $\mathrm{M}_{\mathrm{i}}+\mathrm{C}_{\mathrm{c}} \rightarrow \mathrm{M}_{\mathrm{c}}+\mathrm{C}_{\mathrm{i}}$ & 5.61 & 3.77 & 5.31 & 5.13 & 6.62 & 5.56 & 4.42 \\
\hline 15. & $S n_{i}+M_{M} \rightarrow S n_{M}+M_{i}$ & 2.78 & 1.24 & 3.01 & 1.89 & 3.95 & 4.17 & 4.36 \\
\hline 16. & $\mathrm{Sn}_{\mathrm{i}}+\mathrm{C}_{\mathrm{C}} \rightarrow \mathrm{Sn}_{\mathrm{C}}+\mathrm{C}_{\mathrm{i}}$ & 3.04 & 0.66 & 2.62 & 1.19 & 2.79 & 1.67 & 2.60 \\
\hline 17. & $\mathrm{C}_{\mathrm{i}}+\mathrm{M}_{\mathrm{M}} \rightarrow \mathrm{C}_{\mathrm{M}}+\mathrm{M}_{\mathrm{i}}$ & 5.70 & 5.60 & 6.49 & 7.69 & 8.78 & 10.81 & 8.22 \\
\hline \multirow[t]{2}{*}{18.} & $\mathrm{C}_{\mathrm{i}}+\mathrm{Sn}_{\mathrm{Sn}} \rightarrow \mathrm{C}_{\mathrm{Sn}}+\mathrm{Sn}_{\mathrm{i}}$ & 5.47 & 7.98 & 5.13 & 8.79 & 6.85 & 8.40 & 7.46 \\
\hline & Schottky reaction & 9.78 & 5.83 & 9.99 & 7.97 & 9.69 & 8.57 & 6.70 \\
\hline
\end{tabular}

Table 2 lists the defect reactions and the corresponding defect energies for $\mathrm{Sc}_{2} \mathrm{SnC}$ and the existing $\mathrm{M}_{2} \mathrm{SnC} \mathrm{MAX}$ phases. In these calculations we have considered all the possible point defects including all the interstitial sites existing in the $211 \mathrm{M}_{2} \mathrm{SnC}$ MAX phases. For the defect reactions we employed the Kröger-Vink notation ${ }^{65}$. In this notation $M_{i}$ stands for an $M$ interstitial defect, $V_{s n}$ for a Sn vacant site and $M_{s n}$ an $M$ atom residing in a Sn site (known as antisite defect). Typically, the energies of the Schottky reaction in this system are high (Table 2) and therefore the Frenkel 
reactions (Table 2, relations 1-3) or the antisite reactions (Table 2, relations 4-6) are more relevant when considering the radiation tolerance of the material. For $\mathrm{Sc}_{2} \mathrm{SnC}$ the C-Frenkel energy is only $3.33 \mathrm{eV}$ inferring that this is not a particularly radiation tolerant MAX phase as compared to most of the other MAX phases considered here (Table 2). Commonly, with the other MAX phases in Table 2 there is the possibility to form antisite vacancies via the recombination of self-interstitials and vacancies. For $\mathrm{Sc}_{2} \mathrm{SnC}$ this is inferred by the negative energies in reactions 7-9 and 12 .

\section{Conclusions}

In summary, we have employed DFT calculations to investigate the structural, electronic, mechanical and lattice dynamical properties of $\mathrm{Sc}_{2} \mathrm{SnC}$ including defect processes to compare with those of existing $\mathrm{M}_{2} \mathrm{SnC}$ MAX phases. The calculated structural properties show fair agreement with the experimental values. The structural, mechanical and dynamical stability of $\mathrm{Sc}_{2} \mathrm{SnC}$ is verified. The chemical bonding of $\mathrm{Sc}_{2} \mathrm{SnC}$ is a combination of metallic, covalent and ionic. The softness, machinability, elastic anisotropy level and deformability of $\mathrm{Sc}_{2} \mathrm{SnC}$ are moderate compared to the other $\mathrm{M}_{2} \mathrm{SnC}$ phases. $\mathrm{Sc}_{2} \mathrm{SnC}$ has the potential to be etched into $2 \mathrm{D}$ MXenes and be a promising TBC material, similar to the other $\mathrm{M}_{2} \mathrm{SnC}$ phases. The hardness of $\mathrm{M}_{2} \mathrm{SnC}$, including $\mathrm{Sc}_{2} \mathrm{SnC}$, follows the trend of bulk modulus rather than shear and Young's modulus while the melting point has a better relationship with the bulk and Young's modulus than with the shear modulus. The rate of declination of lattice thermal conductivity with temperature is slower for the $\mathrm{Sc}_{2} \mathrm{SnC}$ phase and faster for the $\mathrm{Ti}_{2} \mathrm{SnC}$ phase. Examining the defect processes of the existing $\mathrm{M}_{2} \mathrm{SnC}$ phases it is revealed that $\mathrm{Sc}_{2} \mathrm{SnC}$ is less radiation tolerant than numerous 211 MAX phases.

\section{References}

1. Nowotny, V. H. Strukturchemie einiger Verbindungen der Übergangsmetalle mit den elementen C, Si, Ge, Sn. Progress in Solid State Chemistry 5, 27-70 (1971).

2. Barsoum, M. W. MAX Phases. (2013)

3. Hadi, M. A. Superconducting phases in a remarkable class of metallic ceramics. Journal of Physics and Chemistry of Solids 138, 109275 (2020).

4. Hadi, M. A., Kelaidis, N., Naqib, S. H., Chroneos, A. \& Islam, A. K. M. A. Electronic structures, bonding natures and defect processes in Sn-based 211 MAX phases. Computational Materials Science 168, 203-212 (2019).

5. Zapata-Solvas, E. et al. Synthesis and physical properties of $\left(\mathrm{Zr}_{1-\mathrm{x}}, \mathrm{Ti}_{\mathrm{x}}\right)_{3} \mathrm{AlC}_{2} \mathrm{MAX}$ phases. Journal of the American Ceramic Society 100, 3393-3401 (2017).

6. Shuck, C. E. \& Gogotsi, Y. MXenes: A Tunable Family of 2D Carbides and Nitrides with Diverse Applications. Material Matters 15, 3-10 (2020).

7. Zhao, S. et al. Electrochemical Interaction of Sn-Containing MAX Phase $\left(\mathrm{Nb}_{2} \mathrm{SnC}\right)$ with Li-lons. ACS Energy Lett. 4, 2452-2457 (2019).

8. $\mathrm{Xu}, \mathrm{Q}$. et al. Theoretical prediction, synthesis, and crystal structure determination of new MAX phase compound $\mathrm{V}_{2} \mathrm{SnC}$. Journal of Advanced Ceramics 9, 481-492 (2020).

9. Chen, K. et al. MAX phase $\mathrm{Zr}_{2} \mathrm{SeC}$ and its thermal conduction behavior. Journal of the European Ceramic Society 41, 4447-4451 (2021).

10. Li Youbing, Q. Y., Chen Ke, Chen Lu, Zhang Xiao, Ding Haoming, Li Mian, Zhang Yiming, Du Shiyu, Chai Zhifang, Huang Qing. Molten Salt Synthesis of Nanolaminated $\mathrm{Sc}_{2} \mathrm{SnC}$ MAX Phase. Journal of Inorganic Materials 36, 773-778 (2021).

11. Toth, L. E., Jeitschko, W. \& Yen, C. M. The superconducting behavior of several complex carbides and nitrides. Journal of the Less Common Metals 10, 29-32 (1966).

12. Clark, S. J. et al. First principles methods using CASTEP: Zeitschrift für Kristallographie Crystalline Materials 220, 567-570 (2005).

13. Perdew, J. P., Burke, K. \& Ernzerhof, M. Generalized Gradient Approximation Made Simple. Phys. Rev. Lett. 77, 3865-3868 (1996). 
14. Vanderbilt, D. Soft self-consistent pseudopotentials in a generalized eigenvalue formalism. Phys. Rev. B 41, 7892-7895 (1990).

15. Monkhorst, H. J. \& Pack, J. D. Special points for Brillouin-zone integrations. Phys. Rev. B 13, 5188-5192 (1976).

16. Fischer, T. H. \& Almlof, J. General methods for geometry and wave function optimization. J. Phys. Chem. 96, 9768-9774 (1992).

17. Murnaghan, F. D. Finite Deformation of an Elastic Solid. (Wiley, New York, 1951).

18. Hadi, M. A. et al. First-principles prediction of mechanical and bonding characteristics of new T2 superconductor Ta5GeB2. physica status solidi (b) 253, 2020-2026 (2016).

19. Hadi, M. A. et al. Elastic and thermodynamic properties of new $\left(\mathrm{Zr}_{3-\mathrm{x}} \mathrm{Ti}_{\mathrm{x}}\right) \mathrm{AlC}_{2} \mathrm{MAX}$-phase solid solutions. Computational Materials Science 137, 318-326 (2017).

20. Rubel, M. H. K. et al. Density functional theory study of a new Bi-based $\left(\mathrm{K}_{1.00}\right)\left(\mathrm{Ba}_{1.00}\right)_{3}\left(\mathrm{Bi}_{0.89} \mathrm{Na}_{0.11}\right)_{4} \mathrm{O}_{12}$ double perovskite superconductor. Computational Materials Science 138, 160-165 (2017).

21. Roknuzzaman, M. et al. First hafnium-based MAX phase in the 312 family, $\mathrm{Hf}_{3} \mathrm{AlC}_{2}$ : A firstprinciples study. Journal of Alloys and Compounds 727, 616-626 (2017).

22. Nasir, M. T. et al. First-Principles Study of Superconducting ScRhP and SclrP pnictides. physica status solidi (b) 254, 1700336 (2017).

23. Christopoulos, S.-R. G. et al. Intrinsic defect processes and elastic properties of $\mathrm{Ti}_{3} \mathrm{AC}_{2}(\mathrm{~A}=\mathrm{Al}, \mathrm{Si}$, $\mathrm{Ga}, \mathrm{Ge}, \mathrm{In}, \mathrm{Sn}$ ) MAX phases. Journal of Applied Physics 123, 025103 (2018).

24. Tanveer Karim, A. M. M. et al. Newly synthesized $\mathrm{MgAl}_{2} \mathrm{Ge}_{2}$ : A first-principles comparison with its silicide and carbide counterparts. Journal of Physics and Chemistry of Solids 117, 139-147 (2018).

25. Hadi, M. A. et al. Physical properties and defect processes of $\mathrm{M}_{3} \mathrm{SnC}_{2}(\mathrm{M}=\mathrm{Ti}, \mathrm{Zr}, \mathrm{Hf}) \mathrm{MAX}$ phases: Effect of M-elements. Journal of Alloys and Compounds 748, 804-813 (2018).

26. Hadi, M. A., Islam, M. N. \& Babu, M. H. Cubic Perovskite $\mathrm{Pb}\left(\mathrm{Mg}_{1 / 3} \mathrm{Nb}_{2 / 3}\right) \mathrm{O}_{3}$ : A Damage Tolerant, Machinable, and Thermal barrier coating material: Zeitschrift für Naturforschung A 74, 71-81 (2019).

27. Filippatos, P. P. et al. 312 MAX Phases: Elastic Properties and Lithiation. Materials 12, (2019).

28. Islam, M. N., Hadi, M. A. \& Podder, J. Influence of Ni doping in a lead-halide and a lead-free halide perovskites for optoelectronic applications. AIP Advances 9, 125321 (2019).

29. Ali, M. M. et al. DFT investigations into the physical properties of a MAB phase Cr4AlB4. Journal of Alloys and Compounds 821, 153547 (2020).

30. Hadi, M. A. et al. Chemically stable new MAX phase $\mathrm{V}_{2} \mathrm{SnC}$ : a damage and radiation tolerant $\mathrm{TBC}$ material. RSC Adv. 10, 43783-43798 (2020).

31. Hadi, M. A., Kelaidis, N., Naqib, S. H., Chroneos, A. \& Islam, A. K. M. A. Mechanical behaviors, lattice thermal conductivity and vibrational properties of a new MAX phase Lu2SnC. Journal of Physics and Chemistry of Solids 129, 162-171 (2019).

32. Barsoum, M. W., Yaroschuk, G. \& Tyagi, S. Fabrication and characterization of $\mathrm{M}_{2} \mathrm{SnC}(\mathrm{M}=\mathrm{Ti}, \mathrm{Zr}$, $\mathrm{Hf}$ and Nb). Scripta Materialia 37, 1583-1591 (1997).

33. Sanchez-Portal, D., Artacho, E. \& Soler, J. M. Projection of plane-wave calculations into atomic orbitals. Solid State Communications 95, 685-690 (1995).

34. Mulliken, R. S. Electronic Population Analysis on LCAO-MO Molecular Wave Functions. I. J. Chem. Phys. 23, 1833-1840 (1955).

35. Born, M. On the stability of crystal lattices. I. Mathematical Proceedings of the Cambridge Philosophical Society 36, 160-172 (1940).

36. Voigt, W. Lehrbuch der Kristallphysik. (Taubner, Leipzig, 1928).

37. Reuss, A. Berechnung der Fließgrenze von Mischkristallen auf Grund der Plastizitätsbedingung für Einkristalle . ZAMM - Journal of Applied Mathematics and Mechanics / Zeitschrift für Angewandte Mathematik und Mechanik 9, 49-58 (1929). 
38. Hill, R. The Elastic Behaviour of a Crystalline Aggregate. Proceedings of the Physical Society. Section A 65, 349-354 (1952).

39. Azzouz-Rached, A. et al. Pressure effects on the structural, elastic, magnetic and thermodynamic properties of Mn2AIC and Mn2SiC MAX phases. Journal of Alloys and Compounds 885, 160998 (2021).

40. Pugh, S. F. XCII. Relations between the elastic moduli and the plastic properties of polycrystalline pure metals. null 45, 823-843 (1954).

41. Hadi, M. A. New ternary nanolaminated carbide $\mathrm{Mo}_{2} \mathrm{Ga}_{2} \mathrm{C}$ : A first-principles comparison with the MAX phase counterpart $\mathrm{Mo}_{2} \mathrm{GaC}$. Computational Materials Science 117, 422-427 (2016).

42. Hadi, M. A. et al. Effects of Al substitution by $\mathrm{Si}$ in $\mathrm{Ti}_{3} \mathrm{AlC}_{2}$ nanolaminate. Scientific Reports 11, 3410 (2021).

43. Ali, M. A., Hadi, M. A., Hossain, M. M., Naqib, S. H. \& Islam, A. K. M. A. Theoretical investigation of structural, elastic, and electronic properties of ternary boride MoAlB. physica status solidi (b) 254, 1700010 (2017).

44. Aryal, S., Sakidja, R., Barsoum, M. W. \& Ching, W.-Y. A genomic approach to the stability, elastic, and electronic properties of the MAX phases. physica status solidi (b) 251, 1480-1497 (2014).

45. Cover, M. F., Warschkow, O., Bilek, M. M. M. \& McKenzie, D. R. A comprehensive survey of M2AX phase elastic properties. Journal of Physics: Condensed Matter 21, 305403 (2009).

46. Wang, X. et al. Mechanical Properties and Damage Tolerance of Bulk $\mathrm{Yb}_{3} \mathrm{Al}_{5} \mathrm{O}_{12}$ Ceramic. Journal of Materials Science \& Technology 31, 369-374 (2015).

47. Cao, X. Q., Vassen, R. \& Stoever, D. Ceramic materials for thermal barrier coatings. Journal of the European Ceramic Society 24, 1-10 (2004).

48. Kube, C. M. Elastic anisotropy of crystals. AIP Advances 6, 095209 (2016).

49. Hadi, M. A., Rayhan, M. A., Naqib, S. H., Chroneos, A. \& Islam, A. K. M. A. Structural, elastic, thermal and lattice dynamic properties of new 321 MAX phases. Computational Materials Science 170, 109144 (2019).

50. Gaillac, R., Pullumbi, P. \& Coudert, F.-X. ELATE: an open-source online application for analysis and visualization of elastic tensors. Journal of Physics: Condensed Matter 28, 275201 (2016).

51. Gou, H., Hou, L., Zhang, J. \& Gao, F. Pressure-induced incompressibility of ReC and effect of metallic bonding on its hardness. Appl. Phys. Lett. 92, 241901 (2008).

52. El-Raghy, T., Chakraborty, S. \& Barsoum, M. W. Synthesis and characterization of $\mathrm{Hf}_{2} \mathrm{PbC}$, $\mathrm{Zr} 2 \mathrm{PbC}$ and $\mathrm{M}_{2} \mathrm{SnC}(\mathrm{M}=\mathrm{Ti}, \mathrm{Hf}, \mathrm{Nb}$ or $\mathrm{Zr}$ ). Journal of the European Ceramic Society 20, 2619-2625 (2000).

53. Anderson, O. L. A simplified method for calculating the debye temperature from elastic constants. Journal of Physics and Chemistry of Solids 24, 909-917 (1963).

54. Fine, M. E., Brown, L. D. \& Marcus, H. L. Elastic constants versus melting temperature in metals. Scripta Metallurgica 18, 951-956 (1984).

55. Morelli, D. T. \& Slack, G. A. High Lattice Thermal Conductivity Solids. in High Thermal Conductivity Materials (eds. Shindé, S. L. \& Goela, J. S.) 37-68 (Springer New York, 2006). doi:10.1007/0-387-25100-6_2.

56. Ali, M. M., Hadi, M. A., Ahmed, I., Haider, A. F. M. Y. \& Islam, A. K. M. A. Physical properties of a novel boron-based ternary compound Ti2InB2. Materials Today Communications 25, 101600 (2020).

57. Clarke, D. R. Materials selection guidelines for low thermal conductivity thermal barrier coatings. Surface and Coatings Technology 163-164, 67-74 (2003).

58. Liu, Y. et al. Discovery of $\mathrm{ABO}_{3}$ perovskites as thermal barrier coatings through high-throughput first principles calculations. null 7, 145-151 (2019).

59. Grimes, R. W. et al. The Effect of Ion Size on Solution Mechanism and Defect Cluster Geometry. Berichte der Bunsengesellschaft für physikalische Chemie 101, 1204-1210 (1997).

60. Sickafus, K. E. et al. Radiation Tolerance of Complex Oxides. Science 289, 748 (2000). 
61. Chroneos, A., Rushton, M. J. D., Jiang, C. \& Tsoukalas, L. H. Nuclear wasteform materials: Atomistic simulation case studies. Journal of Nuclear Materials 441, 29-39 (2013).

62. Horlait, D., Grasso, S., Chroneos, A. \& Lee, W. E. Attempts to synthesise quaternary MAX phases $(\mathrm{Zr}, \mathrm{M})_{2} \mathrm{AlC}$ and $\mathrm{Zr}_{2}(\mathrm{Al}, \mathrm{A}) \mathrm{C}$ as a way to approach $\mathrm{Zr}_{2} \mathrm{AlC}$. null 4, 137-144 (2016).

63. Zapata-Solvas, E. et al. Experimental synthesis and density functional theory investigation of radiation tolerance of $\mathrm{Zr}_{3}\left(\mathrm{Al}_{1-\mathrm{x}} \mathrm{Si}_{\mathrm{x}}\right) \mathrm{C}_{2} \mathrm{MAX}$ phases. J Am Ceram Soc 100, 1377-1387 (2017).

64. Hanson, W. A., Patel, M. K., Crespillo, M. L., Zhang, Y. \& Weber, W. J. Influence of electronic vs nuclear energy loss in radiation damage of $\mathrm{Ti}_{3} \mathrm{SiC}_{2}$. Acta Materialia 161, 302-310 (2018).

65. Kröger, F. A. \& Vink, H. J. Relations between the Concentrations of Imperfections in Crystalline Solids. in Solid State Physics (eds. Seitz, F. \& Turnbull, D.) vol. 3, 307-435 (Academic Press, 1956).

\section{Acknowledgements}

The authors wish to acknowledge the High-Performance Computing (HPC) facility at Coventry University, Priory Street, Coventry CV1 5FB, UK for providing the computational facility to calculate the defect processes in newly synthesized $\mathrm{Sc}_{2} \mathrm{SnC}$ MAX phase.

\section{Author contribution}

M.A.H. conceived the study and prepared all figures. M.A.H. and S.-R.G.C. carried out the calculations. M.A.H. and A.C. wrote the main manuscript text. All authors reviewed the manuscript.

\section{Competing interests}

The authors declare no competing interests.

\section{Data Availability}

Data will be provided on reasonable request.

\section{Additional information}

Supplementary Information The online version contains supplementary material available at https://

Correspondence and requests for materials should be addressed to M.A.H. 


\section{Supplementary Files}

This is a list of supplementary files associated with this preprint. Click to download.

- SupplementaryInformationSc2SnC.docx 